Kapitel II

\title{
Dekorative (Un)fertigkeit. Zum Prozess des Beschreibens auf einer Gruppe von spätarchaisch- frühklassischen Statuenbasen aus Athen
}

von Johannes Fouquet

\section{Vorbemerkung}

In der ersten Hälfte des 5. Jhs. v. Chr. lässt sich unter den in attischen Heiligtümern gestifteten figürlichen Votiven und in kleinerer Zahl unter den andernorts errichteten statuarischen Monumenten eine Reihe von Basen ausmachen, die durch eine besondere Zurichtung auffallen: Allesamt weisen sie nämlich Anzeichen einer im Zwischenstadium des Fertigungsprozesses verharrenden ,Unfertigkeit‘ auf. Das äußert sich vornehmlich in Form eines stehen gelassenen Werkzolls bzw. einer Bossierung oder aber in einer anathyroseartigen Bearbeitung ihrer Stirnseiten. Dieses Phänomen ist der Forschung seit längerem bereits bekannt, aber noch nicht vollends erklärt und verstanden. Sicherlich handelt es sich bei den Basen nicht um wiederverwendete Bauglieder, wie bereits James H. Oliver erkannte, sondern um eine absichtsvolle Schmuckform. ${ }^{300}$ Zuletzt hat sich Catherine Keesling mit der von ihr als ,, architectural style“ bezeichneten Gestaltungsweise auseinandergesetzt und eine erste, im Einzelnen noch erweiterbare Zusammenstellung der entsprechenden Statuenbasen vorgenommen. Dabei hat der „architectural style“ nach dem Urteil Keeslings gerade nach 480 v. Chr. unter semantischen Gesichtspunkten eine besondere Emphase erfahren, nämlich als Sinnbild der unfertig gebliebenen Bauglieder des von den Persern zerstörten Vorparthenon, die zur Verbreitung beigetragen habe. ${ }^{301}$ Der Begriff ,,architectural style“ erscheint allerdings zu eingeschränkt, weil er ein wesentliches Charakteristikum dieser Oberflächengestaltung nicht erfasst: Sie visualisiert eben nicht, das Gebaute، im Allgemeinen, sondern vielmehr ,das unfertige Gebaute، im Speziellen.

Dabei blieb in der Forschung bislang ein wesentlicher Aspekt noch gänzlich unbeachtet, nämlich die Faktur des Geschriebenen auf diesen ,unfertigen“ Statuenbasen selbst. Wie im Rahmen dieses Bandes deutlich wird, ${ }^{302}$ zeichnet sich die Anbringung

300 Oliver 1933, 484 bezeichnet die Gestaltungsweise als „, decorative feature“. So auch Dinsmoor 1967-1968, 153f.; Kalpaxis 1986, 123-125. Für eine Identifikation der Basen als Bauglieder dagegen etwa Raubitschek/Stevens 1946, 110; Raubitschek ad DAA 160; Rumpf 1964, 144. Ohne ausdrückliche Stellungnahme in dieser Frage: Lauffer 1937, 85; Jacob-Felsch 1969, 49; Kaczko 2016, 288.

301 Keesling 2010, 126-128.

302 Siehe hier Kapitel I und Kapitel III.

Ә Open Access. (C) 2020 Johannes Fouquet, publiziert von De Gruyter. (c) BY-NC-ND Dieses Werk ist lizenziert unter der Creative Commons Attribution-NonCommercial-NoDerivatives 4.0 Lizenz.

https://doi.org/10.1515/9783110645422-003 
von Inschriften auf Bildwerken und ihren Basen in archaischer Zeit charakteristischerweise durch eine Konzeption ihres Layouts aus, die den Schreibgrund nicht als abstrakt-autonomen Raum begreift, sondern vielmehr die Objekte im engeren Sinne beschriftet. Leere Oberflächenpartien werden mit Geschriebenem ,gefüllt', das eine ausgeprägt graphisch-ornamentale Qualität aufweist. ${ }^{303}$ Das wird etwa am Beispiel einer hocharchaischen Kore aus dem boiotischen Ptoion deutlich: In weiten Bögen des boustrophedon steht die Weihinschrift gleichsam einer mäandrierenden Stofffalte auf dem ansonsten plastisch nicht näher differenzierten Saum ihres Chiton. ${ }^{304}$

Im Gegensatz zu den Regionalstilen Boiotiens und gerade auch des ionischen Raumes spielte die Anbringung von Inschriften auf den Statuen selbst für den attischen epigraphical habit keine nennenswerte Rolle: Inschriften wurden in aller Regel auf die Basen der Bildwerke gesetzt. ${ }^{305}$ Dennoch lässt sich auch hier das zuvor konstatierte Phänomen des beschrifteten statuarischen Monuments beobachten, wie der Deckblock vom Pfeilermonument der Antenor-Kore exemplarisch veranschaulicht (Abb. 3.5). ${ }^{306}$ Auf seiner Front orientieren sich die einzelnen, regelmäßig platzierten Buchstaben der in stoichedon angelegten Weihinschrift eng an den Außenkanten, zwischen denen das Geschriebene geradezu netzartig aufgespannt wird. Der Schreibgrund ist damit kein abstrakter, losgelöster Raum, sondern eng an die Materialität des Blockes gebunden. Der ausgeprägte Ornamentcharakter des Geschriebenen wird durch die Symmetrie einfordernde scriptio continua zusätzlich verstärkt, die Worttrennungen allein anhand des zur Verfügung stehenden Raumes und nicht etwa anhand von textimmanenten Kriterien wie z. B. von Wortsilben bemisst. Der eigentliche Text verliert damit zwar nicht an Bedeutung, denn er wird trotz alledem sicherlich gelesen worden sein. Er tritt aber in seiner autonomen Semantik hinter der Prägnanz des Schriftbildes zurück: Das Geschriebene und sein Träger sind konzeptioneller Teil des Gesamtbildwerks. ${ }^{307}$

Für die Frage, inwieweit mit einer analogen Faktur des Geschriebenen auf den hier vorzustellenden ,unfertigen' Statuenbasen zu rechnen ist, ist ein weiterer Aspekt wesentlich: Im Hinblick auf die Gestaltung ihrer beschrifteten Stirnseiten zeichnet sich die überwiegende Mehrheit der archaischen Statuenbasen durch eine einheitliche Zurichtung aus, wobei der Schreibgrund entweder sorgfältig geglättet wurde

303 Dietrich 2017a, 289-294. Zum Ornamentcharakter von Schrift, speziell von Inschriften siehe auch Butz 2009; Grüner 2014. Allgemein zum Ornament in der archaischen Plastik anhand der begrifflichen Kategorien von „symmetry“, „repetition“ und „geometric precision“: Dietrich 2018c.

304 IG VII 2729. Richter 1968, 26f. Nr. 2; Kokkorou-Alevras 2014, 15-17 und Abb. $22-24$ (mit Lit.).

305 Vgl. Jeffery 1961, 328. Für eine Synopse beschrifteter Korai: Richter 1968, 324; vgl. Karakasi 2001, 25-30, 47f., 76f., 133-135. Ebenso für Kouroi: Richter 1970, 360. Das gilt auch im Falle der Kleinkunst, vgl. Johnston 1993, 42 für beschriftete Bronzestatuetten archaisch-frühklassischer Zeit.

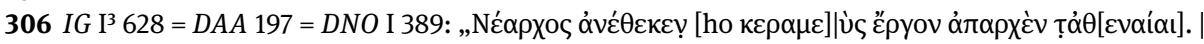

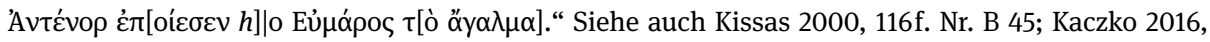
$72-82$ Nr. 15.

307 Dietrich 2017a, 289-292. 
oder seltener eine in der Qualität variierende Zahnung bzw. Scharrierung aufweist. ${ }^{308}$ Farblich gefasste Rahmen, die vorwiegend anhand von Ritzlinien nachweisbar sind, plastisch gearbeitete Leisten oder figürliche Darstellungen blieben demgegenüber in der Minderheit und, mehr noch, waren gerade in Kombination mit Inschriften selten. ${ }^{309}$ Vor dem Hintergrund der neuartigen Konzeption dieser Gruppe von Statuenbasen drängt sich deshalb umso mehr die Frage nach Veränderungen im Status des Geschriebenen am Bildträger auf. Antworten darauf kann allein eine intensive Nahsicht des Materials bieten.

$\mathrm{Zu}$ diesem Zweck soll im Folgenden die Gruppe der spätarchaisch-frühklassischen statuarischen Monumente mit dekorativer Unfertigkeit getrennt nach Art der Oberflächengestaltung eingehender auf die Praxis des Beschreibens hin analysiert werden, wobei, wie eingangs dargelegt, zwischen Werkzoll und Bossierung sowie einer anathyroseartigen Bearbeitung unterschieden wird. Am Beispiel der Basis der Phrasikleia-Kore, eines, wie noch zu zeigen ist, motivisch frühen Vorläufers, wird der ionische Ursprung dieser Schmuckform und ihre erste Verbreitung in Athen durch die Präsenz von ionischen Bildhauern näher erläutert. Ihr dekorativer Charakter soll abschließend in Gegenüberstellung zu Keeslings Hypothese einer Semantisierung als lieu de mémoire im kollektiven Gedächtnis der Polis nach den Perserkriegen erhärtet werden.

\section{Werkzoll und Bossierung an Säulen- und Blockbasen}

$\mathrm{Zu}$ den frühesten Votiven mit einer ,unfertigen' Oberflächengestaltung, die von der Athener Akropolis stammen, zählen die anhand ihrer Buchstabenformen ins frühe 5. Jh. v. Chr. datierten Säulenanatheme des Arist[---] und des Xenokles (Kat. 2.13-14, Abb. 2.1). In beiden Fällen handelt es sich im Gegensatz zu dem im 6. Jh. v. Chr. üblichen Typus des kannelierten Säulenanathems um einen unkannelierten Säulenschaft, dessen Oberfläche nach Art eines Werkzolles grob gespitzt wurde. ${ }^{310}$ Im Falle

308 Dementsprechend zeichnet sich etwa für die Quaderbasen von der Athener Akropolis in der ersten Hälfte des 5. Jhs. v. Chr., soweit nachvollziehbar, folgendes Bild ab. Insgesamt 46 Exemplare mit geglätteter schrifttragender Seite: $D A A$ 72, 76, 82, 85-87, 90, 93-95, 97, 98, 101-102, 104-110, 113-114, 116, 120-121, 123-127, 130, 132, 135, 151-159, 162, 171, 173. Dem stehen insgesamt 17 Exemplare mit gezahnter bzw. scharrierter schrifttragender Seite gegenüber: $D A A 71,73,75,77-81,83,88-89,99-100$, 117, 128, 134, 163. Zu einer entsprechenden Oberflächenbearbeitung als Schmuckform archaischer Zeit: Dirschedl 2017.

309 Zu Rahmen: Keesling 1999, 519f.; siehe oben Kapitel I, S. 72-76. Zu Basen mit figürlichen Darstellungen: Kosmopoulou 2002, 36-63. Allgemein zur Rahmung von Inschriften: Day 2010, 50-52.

310 Keesling 2010, 126f. bezeichnet diese Bearbeitung unter Bezugnahme auf die noch zu besprechende Kallimachos-Säule (Kat. 2.17) als „architectural anathyrosis“ bzw. „pseudo-anathyrosis“. Dafür fehlt es diesen Stücken aber an einem Randschlag, wie er an der von Kritios und Nesiotes geschaffenen Rundbasis Kat. 2.10 (siehe unten) nachweisbar ist. 
des Weihgeschenks von Arist[---] wurde dazu ein schmaler vertikaler Streifen mehr oder weniger sorgfältig geglättet, um als Schreibgrund für die jeweilige Weihinschrift zu dienen. Seine Ausmaße orientieren sich eng an dem Platzbedarf der Inschrift, von dem man also zumindest eine rudimentäre Vorstellung haben musste. Ähnliches gilt auch für eine jüngere Säulenbasis aus den Jahren nach 480 v. Chr. (Kat. 2.18): Auch hier wurde die freilich kaum erhaltene Weihinschrift wiederum auf einem geglätteten vertikalen Streifen angebracht. Ein anderer Fertigungsprozess lässt sich hingegen an der zuvor erwähnten Säulenschaftbasis des Xenokles beobachten, die womöglich eine bronzene Hydria trug. ${ }^{311}$ In diesem Fall wurde in einem ersten Arbeitsschritt die Inschrift in den Säulenschaft eingemeißelt, den man zuvor bereits mit dem Zahneisen rudimentär geglättet hatte. Erst in einem zweiten Schritt wurde die Oberfläche um die Inschrift herum mit dem Spitzeisen bossiert. Offensichtlich war der Säulenschaft also ursprünglich nicht für diese Gestaltung bestimmt, woran sich weitere Überlegungen zu den Produktionsabläufen in den spätarchaisch-frühklassischen Bildhauerwerkstätten anschließen ließen, die ja in aller Regel nur Auftragsarbeiten übernahmen. Gänzlich auf eine Glättung verzichtete man hingegen im Falle einer stark fragmentarisch erhaltenen Säulenbasis (Kat. 2.16), die an der Westküste Attikas im Gebiet der Deme Aixone, dem modernen Voula, gefunden wurde. Ihre vertikale Weihinschrift, die anhand der Buchstabenformen in die Zeit um 500-480 v. Chr. datiert wurde, wurde direkt in die gespitzte Oberfläche eingemeißelt.

Ein Vergleich dieser Art der Anbringung mit der Beschriftungspraxis von kannelierten Säulenanathemen, bei der man die Weihinschriften in die vertikalen Kanneluren setzte, liegt auf der Hand. Tatsächlich büßten kannelierte Säulenbasen aber seit dem frühen 5. Jh. v. Chr. offenbar an Popularität ein. Denn während noch im vorangehenden Jahrhundert alle Säulenanatheme von der Akropolis tatsächlich auch kanneliert waren, verzichtete man nunmehr in zunehmenden Maße auf die Ausarbeitung der Schäfte. ${ }^{312}$ Lässt sich darin bereits per se eine zunehmende Beliebtheit des ,Unfertigen“ in einer freilich sehr allgemeinen Form erkennen, bietet die Mehrheit der unkannelierten Säulenbasen für die hier verfolgte Frage aber keinen größeren Erkenntnisgewinn, da ihre Schäfte nach üblicher Praxis entweder geglättet, scharriert oder gezahnt und daraufhin ohne Weiteres beschrieben wurden. ${ }^{313}$ Dessen ungeachtet stützt die generell zunehmende Verbreitung von unkannelierten Säulenbasen die

311 Keesling 2005, 417f.

312 Für die kannelierten Säulenbasen des 6. Jhs. v. Chr.: DAA 2-10, 41; vgl. Kissas 2000, 235-238 Nr. B 191-198. Aus den Jahren um 500-480 v. Chr. sind 12 kannelierte Säulenbasen bezeugt: DAA 11-21, 55; vgl. Kissas 2000, 240-242 Nr. B 201-208. Dem stehen 16 unkannelierte Exemplare gegenüber: DAA 23, 24, 28-37, 40, 43-45 vgl. Kissas 2000, 242-246 Nr. B 210-222.

313 Zumindest an dem Säulenschaftfragment $D A A 37=I G \mathrm{I}^{3} 761$ (um 500-480 v. Chr.) lässt sich aber in kleinerem Umfang eine vorbereitende Glättung der gezahnten Oberfläche vor dem Einmeißeln der in stoichedon angelegten Weihinschrift beobachten. Anders als bei den gespitzten unkannelierten Säulenschäften galt das allerdings nur dem unmittelbaren Schreibgrund der einzelnen Buchstaben. Vgl. Kissas 2000, 245 Nr. B 219. 


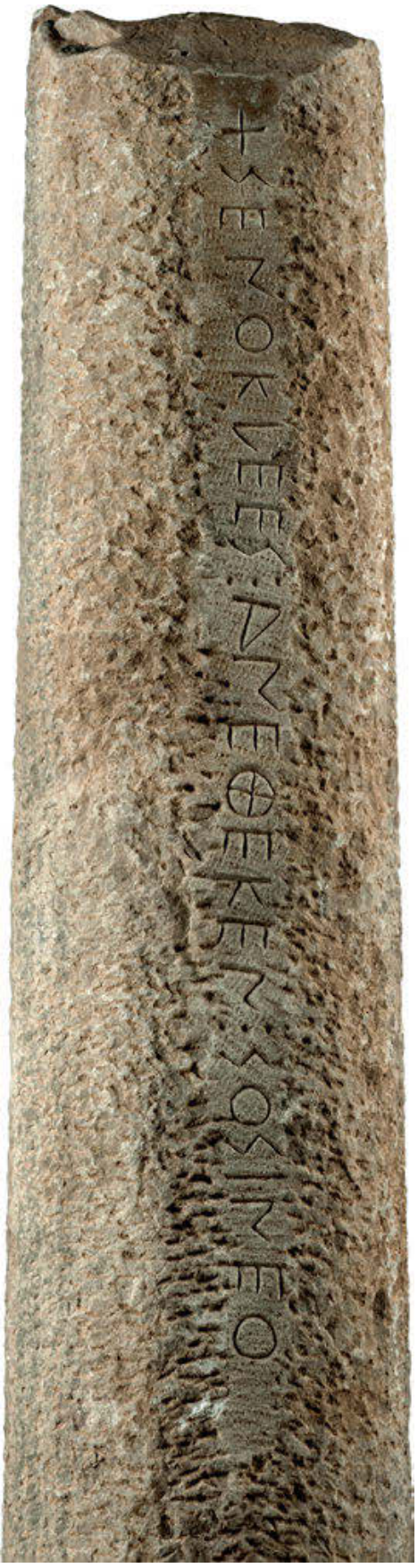

Abb. 2.1: Säulenschaftbasis des Xenokles, um 500-480 v. Chr. (Athen, Akropolis-Museum 6960).

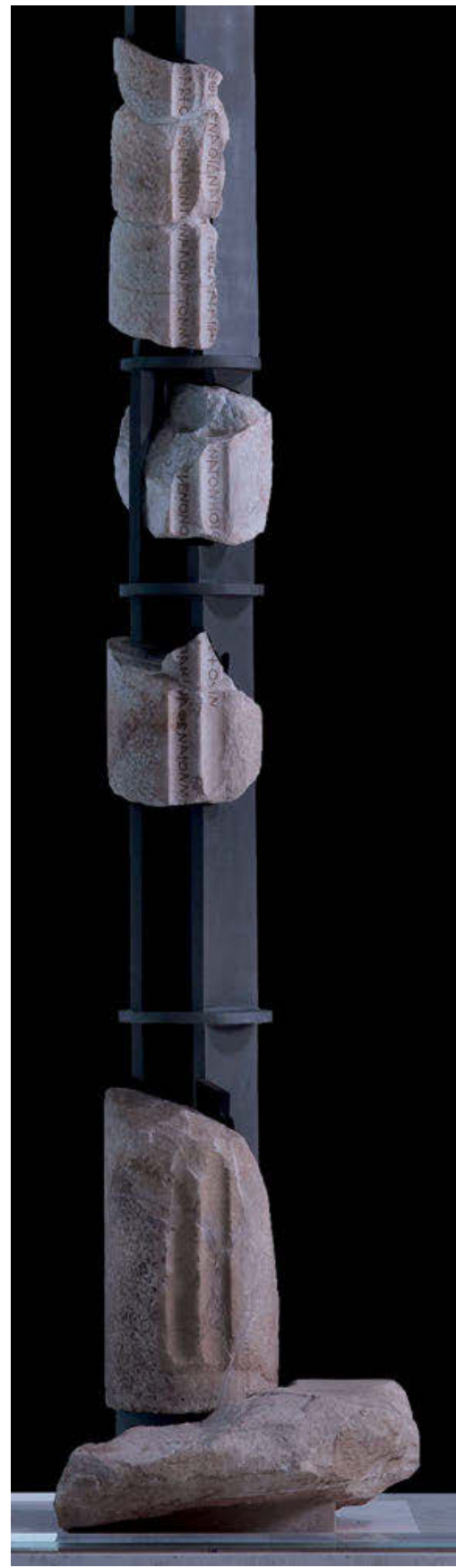

Abb. 2.2: Säulenbasis des Kallimachos, nach 490 v. Chr. (Athen, AkropolisMuseum 6339). 
Vermutung, dass es sich bei den auf wenige Exemplare beschränkten grob gespitzten Schäften eben nicht um im eigentlichen Sinne unfertige Bauglieder handelt, sondern dass der Grad ihrer Bearbeitung vielmehr eine spezifische Konzeption von Unfertigkeit als Dekormotiv widerspiegelt.

Im Rahmen dieser generellen Entwicklung lassen sich verschiedene Mischformen beobachten. Unter ihnen ragt die wohl kurz nach der Schlacht von Marathon im Jahre 490 v. Chr. angefertigte Säulenbasis des Kallimachos (Kat. 2.17), die eine geflügelte Nike trug, als qualitätsvollstes und prominentestes Exemplar heraus. In den ansonsten grob gespitzten, äußerst fragmentarisch erhaltenen monolithen Säulenschaft hatte man zwei Kanneluren der ionischen Ordnung gearbeitet, sie waren als elaboriertere Form der einfachen Glättung Schreibgrund für zwei Epigramme von unterschiedlicher Länge (Abb.2.2). Seit der Auffindung der Fragmente führt die Forschung eine kontroverse Diskussion um die Ergänzung und das Verhältnis der beiden Texte. Es handelt sich zum einen um die eigentliche Weihung durch Kallimachos, zum anderen um die Kommemoration des bei Marathon Gefallenen, der dort als polemarchos sein Leben gelassen hatte. ${ }^{314}$ Denn „dead men do not make dedications“, wie das heuristische Dilemma um die Kallimachos-Basis pointiert zusammengefasst wurde. ${ }^{315}$ Stichhaltige Indizien für eine nachträgliche Einarbeitung einer der beiden Kanneluren können indes nicht angebracht werden, ${ }^{316}$ zumal sie sich ja auch in erheblicher Weise auf die symmetrisch-axiale Ausrichtung von Säulenschaft, Geschriebenem, Kapitell und Statue auswirken würde, so dass man in diesem Fall vielleicht eher einer Beschriftung der gegenüberliegenden Seite des Säulenschaftes den Vorzug gegeben hätte. Es erscheint deshalb am plausibelsten, dass dem Monument eine einzige, einheitliche Konzeption zugrunde liegt. ${ }^{317}$ Dementsprechend könnte es, wie sich in der jüngeren Forschung durchzusetzen scheint, auf ein vor der Schlacht gegebenes Gelübde des Kallimachos zurückgehen, das schließlich von Verwandten oder von der Polis für den Verstorbenen eingelöst wurde. ${ }^{318}$

314 Einen guten Überblick über die unterschiedlichen Forschungspositionen bieten Keesling 2010, 106-108; Kaczko 2016, $285 \mathrm{f}$.

315 Meiggs/Lewis 1988, 33f. Nr. 18 (Zitat auf S.33).

316 Vgl. Shefton 1950, 143f. Aus epigraphischer Perspektive sprach sich Harrison 1971, 18 dafür aus, dass die Inschriften zu unterschiedlichen Zeitpunkten in die Kanneluren eingemeißelt wurden; dagegen Jeffery/Lewis ad IG $\mathrm{I}^{3} 784$,uno tempore incisi sunt“.

317 So vermag denn auch das von Meiggs/Lewis 1988, 33 vorgebrachte Argument für eine graduelle Anlage der beiden Kanneluren nicht zu überzeugen, was vermeintlich erhärtet werde durch ,the cutting of two flutes only, whereas all other inscribed columns known to us are either plain or fluted all round.“

318 So auch trotz Bedenken Meiggs/Lewis 1988, 33; dezidiert Keesling 2010, bes. 115; Kaczko 2016, 287. Für eine private Weihung Jung 2006, 83. Vgl. Franssen 2011, 161-163. Alternativ zu dieser Deutung schlägt Kaczko 2016, 287f. eine Instandsetzung eines älteren Weihgeschenks des Kallimachos vor, das man um das zweite Epigramm ergänzt habe, womit man freilich erneut auf das bereits genannte Problem einer asymmetrischen Konzeption stößt. 


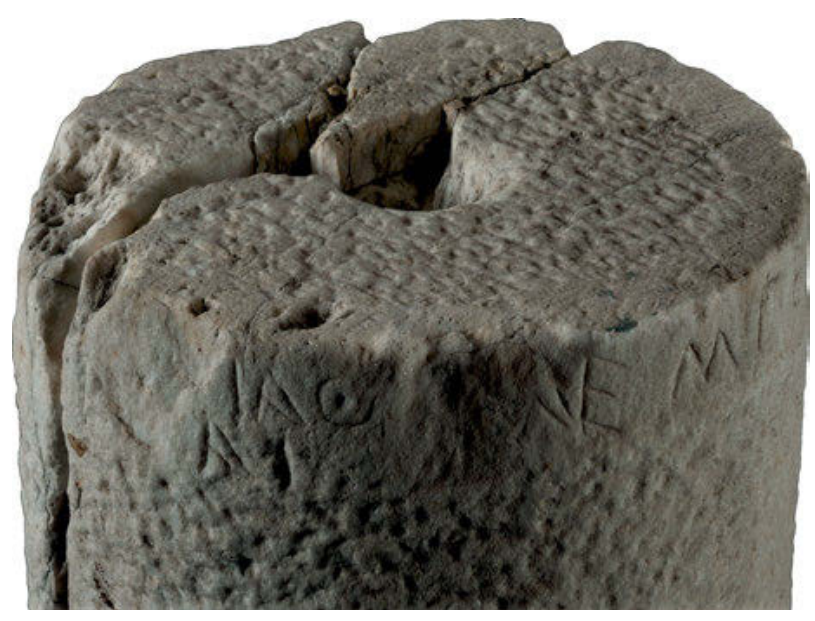

Abb. 2.3: Säulenbasis der Empedia, um 500-480 v. Chr. (Athen, Akropolis-Museum 13396).

In Variation zur vertikalen Anbringung von Inschriften, entweder in einem geglätteten Feld oder, wie zuletzt gesehen, in Kanneluren, wurde bei dem einige Jahre älteren, um 500-480 v. Chr. entstandenen Weihgeschenk der Empedia für Athena (Kat. 2.15) die Weihinschrift gleichsam einem Ornamentband auf einem geglätteten horizontalen Saum am Hals des ansonsten gespitzten Säulenschaftes eingemeißelt (Abb. 2.3). ${ }^{319}$ Die horizontale Anbringung der Inschrift an einem Säulenhals birgt freilich Probleme, denn anders als bei einem vertikalen Layout ist der Platz weitaus limitierter. So wurden die Buchstaben der Empedia-Inschrift zwar zunächst in gleichmäßigen Abständen eingemeißelt. Schließlich sah sich der Steinmetz aber gezwungen, die Empfängerin der Weihung ( $\tau \tilde{\varepsilon} \iota$ 'A $\theta \varepsilon v \alpha i ́ \alpha ı)$ in kleineren Buchstaben anzubringen und zudem auch die letzten drei Buchstaben taı unter den Artikel $\tau \tilde{\varepsilon} \iota$ zu setzen. ${ }^{320}$

Ein weitaus üblicherer Ort für die Anbringung von horizontalen Inschriften an Säulen- und Pfeilerbasen stellten deshalb die Abakusplatten dar, wofür etwa der eingangs erwähnte Deckblock der Antenor-Kore paradigmatisch ist. ${ }^{321}$ Allein, für die ,unfertigen' Säulenbasen lässt sich eine derartige Lösung erst im mittleren 5. Jh. v. Chr. beobachten. Es handelt sich um zwei um 460-450 v. Chr. auf der Akropolis errichtete Anatheme (Kat. 2.19-20), deren Schäfte und Kapitelle grob gespitzt wurden, wovon lediglich die Abaki mit den in stoichedon verfassten Weihinschriften ausgenommen

319 Dekorbänder an Säulenhälsen, nämlich in Form von Anthemien, findet sich vergleichsweise häufig in der archaischen Architektur Ioniens, siehe dazu Pedersen 1983.

320 In ähnlicher Weise hat man bei der im frühen 5. Jh. v. Chr. entstandenen Säulenbasis DAA 55 die Künstlersignatur ( $I G \mathrm{I}^{3}$ 645) auf den Hals oberhalb der Kanneluren gesetzt, während die eigentliche Weihinschrift ( $I G \mathrm{I}^{3}$ 820) in den Abakus des Kapitells eingemeißelt wurde; vgl. Kissas 2000, $206 \mathrm{f}$. Nr. B 162.

321 Zur Antenor-Kore und ihrem Deckblock siehe hier Anm. 306. Exemplarisch für eine Beschriftung des Abakus an archaischen Säulenanathemen mit dorischen Rundkapitellen: Kissas 2000, 201-207 Nr. B 157-163. Für beschriftete Abakusplatten an archaischen Grabsäulen siehe etwa IG IX 1, 869 (Kerkyra); CEG I 136 (Heraion von Argos); vgl. McGowan 1995. 


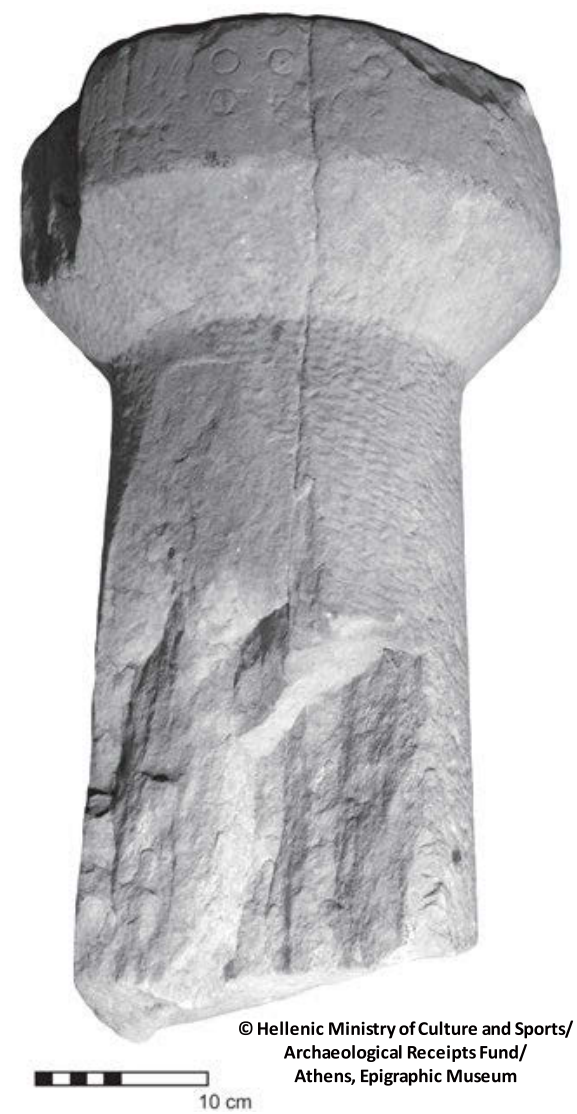

Abb. 2.4: Säulenbasis des Timotheos, um 460-450 v. Chr. (Athen, Epigraphisches Museum 6375).

sind. Der Stifter der Säulenbasis Kat. 2.20 (Abb. 2.4), Timotheos, ist sicherlich mit dem Vater des berühmten nauarchos Konon zu identifizieren. ${ }^{322}$ Schlaglichtartig zeigt sich damit wie auch an der Kallimachos-Säule (Kat. 2.17) bzw. der noch näher zu besprechenden Kallias-Basis (Kat. 2.4), dass das Phänomen der dekorativen Unfertigkeit auch den Repräsentationsbedürfnissen einer der sozialen Führungsgruppe Athens entstammenden Familie Rechnung tragen konnte.

Neben den Säulenbasen lassen sich auch an einigen wenigen Blockbasen grob gespitzte Oberflächen beobachten. An einer orthostatenartigen Blockbasis aus den Jahren um 500-480 v. Chr. (Kat. 2.3) wurde ein Streifen an der Oberkante des gespitzten Blockes geglättet, um hier in zwei horizontalen Zeilen die retrograde Weihinschrift an Apollon einzumeißeln. Im Bemühen, die Breite des Blockes möglichst vollständig zu füllen, nahm man bemerkenswerterweise in Kauf, dass der getrennt über zwei Zeilen verteilte Name des Gottes als Konsequenz der retrograden Schreibweise in weiter

322 Raubitschek ad DAA 47, der die Basis als athletische Siegerweihung interpretierte. Zum sozialen Status der Familie: Davies 1971, 506-512 Nr.13700; March 2008, 139-141. 


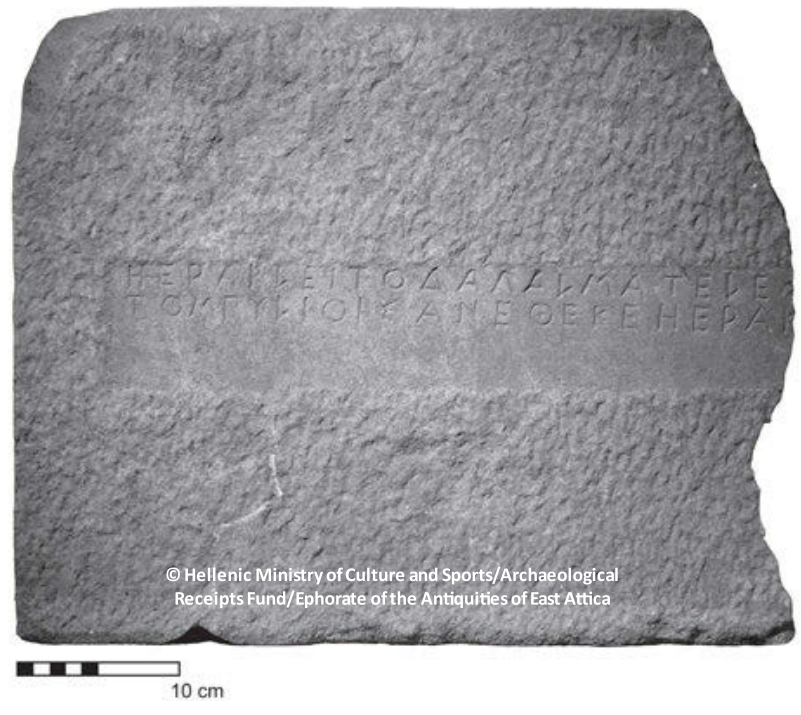

Abb. 2.5: Basisblock des Teles(tes), um $440 \mathrm{v}$. Chr. (Marathon, Museum BE 34).

Sperrung an beiden Blockenden saß. ${ }^{323}$ Der Typus der Basis, v. a. aber die Bettungen, die für kleinere Bronzestatuetten auf der Oberseite eingelassen waren, lassen an eine Votivbank denken. ${ }^{324}$ Die genaue Herkunft des Stückes, das nach mehreren Wiederverwendungsphasen schließlich als Spolie in der hellenistischen Brüstung der Klepsydra am Fuß der Akropolis verbaut wurde, bleibt hingegen unsicher. ${ }^{325}$

Aussagekräftiger unter dem Aspekt des Beschreibprozesses ist ein fragmentarischer, nur in seiner linken Partie erhaltener Inschriftenblock (Kat. 2.23), der in der Marathon-Ebene nördlich des Sumpfes von Brexiza gefunden wurde (Abb. 2.5). Gemäß der Weihinschrift, die in die Zeit nach dem mittleren 5. Jh. v. Chr. datiert wird und auf ein dem Herakles geweihtes agalma Bezug nimmt, dürfte es sich ursrpünglich wohl um ein statuarisches Monument gehandelt haben. Die genaue Rekonstruktion bleibt indes problematisch: Die fein gespitzte Oberseite, die, soweit fassbar, keinerlei Spuren einer Statuenbettung aufweist, könnte womöglich in Form einer Stufenbasis die Plinthe mit dem Bildwerk getragen haben. ${ }^{326}$ Bei dem ursprünglichen Aufstellungsort muss es sich wohl um das bekannte Herakles-Heiligtum handeln, wo das

323 Vgl. in diesem Zusammenhang oben Kapitel I, S. 70 mit Anm. 200.

324 Keesling 2005, 399-401. Zum Typus der Orthostatenbasis: $D A A 80=I G \mathrm{I}^{3}$ 802; vgl. Kissas 2000, 267f. Nr. C 48.

325 Zur Diskussion um die mögliche Herkunft des Blockes aus einem der Apollon-Heiligtümer aus dem Umfeld der Akropolis: Nulton 2003, 25; Keesling 2005, 399f. mit Anm. 21.

326 Für eine Identifikation als Basis: Marinatos 1972, 6; Hansen ad CEG I 318; Jeffery/Lewis ad IG I³ 1015bis; zögerlich Kaczko 2016, 501. Matthaiou 2003, 191 wollte den Block als „architectural member of a monument“ deuten. Dafür fehlt es indes an Spuren einer Verklammerung. Bei der teilweise intakten linken Schmalseite scheint es sich m. E. nicht um eine Anathyrose, sondern um die auf Sicht gearbeitete Quaderstirn zu handeln. Dafür spricht die flache Ausarbeitung, die mit der Zurichtung der Oberseite vergleichbar ist. 
athenische Heer vor der Schlacht von Marathon zusammengezogen wurde. ${ }^{327}$ In die grob gespitzte Front der Basis wurde, um die Weihinschrift anzubringen, ein rechteckiges geglättetes Feld eingetieft. Anders als bei den bereits besprochenen ,unfertigen' Säulenbasen entsprach der auf diese Weise vorbereitete Schreibgrund aber nicht dem tatsächlichen Platzbedarf: Die zweizeilige, in stoichedon verfasste Inschrift nimmt nämlich weniger als die Hälfte der zur Verfügung stehenden Fläche ein, wobei man dieses Missverhältnis leichthin durch ihre zentrale Platzierung hätte ausgleichen können. Ganz im Gegenteil jedoch drängen sich die Buchstaben der ersten Zeile wie an der Deckplatte der Antenor-Kore dicht an die Oberkante des geglätteten Feldes. Seine Funktion ist damit nicht etwa die eines qua Rahmung autonomen Schreibgrundes, sondern es entsteht vielmehr ein imaginärer ,Block im Block ${ }^{3}{ }^{328}$ Offensichtlich besteht also zwischen der zentralen Platzierung des geglätteten Feldes und der Position der Inschrift innerhalb desselben eine kategoriale Differenz, die sich durch die Diskrepanz einer Symmetrie des ,Gebauten' und einer eng an der Materialität orientierten Praxis des Beschriftens begründet.

\section{Randschlag und Spiegel}

Neben der zuvor dargelegten Konzeption von dekorativer Unfertigkeit als Werkzoll oder Bossierung und den Formen ihrer Beschriftung lässt sich, wie eingangs bereits erwähnt, an verschiedenen spätarchaisch-frühklassischen Basen darüber hinaus auch eine anathyroseartige Zurichtung ihrer Stirnseiten beobachten. Im Sinne des ,unfertig Gebauten“ wird damit eine eigentlich „,unsichtbare“ Werkstufe“ offengelegt, die in ihrer Materialität, nämlich durch den Kontrast von Randschlag und Spiegel in den Worten Hans Lauters „,den Reiz der Rauheit und des Ungeschliffenen vermittelt““.329

Eines der frühesten Beispiele dafür ist die Stufenbasis des kitharoidos Alkibios (Kat. 2.1), die wohl noch in die letzten Jahre des 6. Jhs. v. Chr. zu datieren ist. Unter typologischen Gesichtspunkten lässt die ansonsten nahezu singuläre Hufeisenform des fragmentarisch erhaltenen Basisblocks das Innovationspotential des Steinmetzes vor Augen treten. ${ }^{330}$ Da Einlassungsspuren auf seiner Oberseite fehlen, muss es sich um

327 Hdt. 6, 108, 1. Vgl. Marinatos 1972, 6; Travlos 1988, 219; Matthaiou 2003.

328 Vgl. die Beschriftung der um 440 v. Chr. entstandene Quaderbasis Kat. 2.8. Auf dem gespitzten Spiegel wurde mit dem Zahneisen ein rechteckiges Feld rudimentär geglättet, um als Schreibgrund zu dienen. Die erhaltenen Buchstaben sind nicht zentriert, sondern orientieren sich an der Oberkante des Feldes.

329 Lauter 1986, 299.

330 Eine in Form und Dekor vergleichbare Basis ist nach Dinsmoor/Dinsmoor 2004, 63 im Fundament der Westfassade der Propyläen verbaut worden. Die freiliegenden Seiten der hufeisenförmigen Basis weisen eine gespitzte Oberfläche auf, die an Kopf und Fuß von einem glatten Randschlag eingefasst wird. Irrtümlich konstatiert dagegen Kissas 2000, 102, dass es sich um das einzige Beispiel dieser Basisform handelt. Unerwähnt bleibt sie bei Jacob-Felsch 1969. 


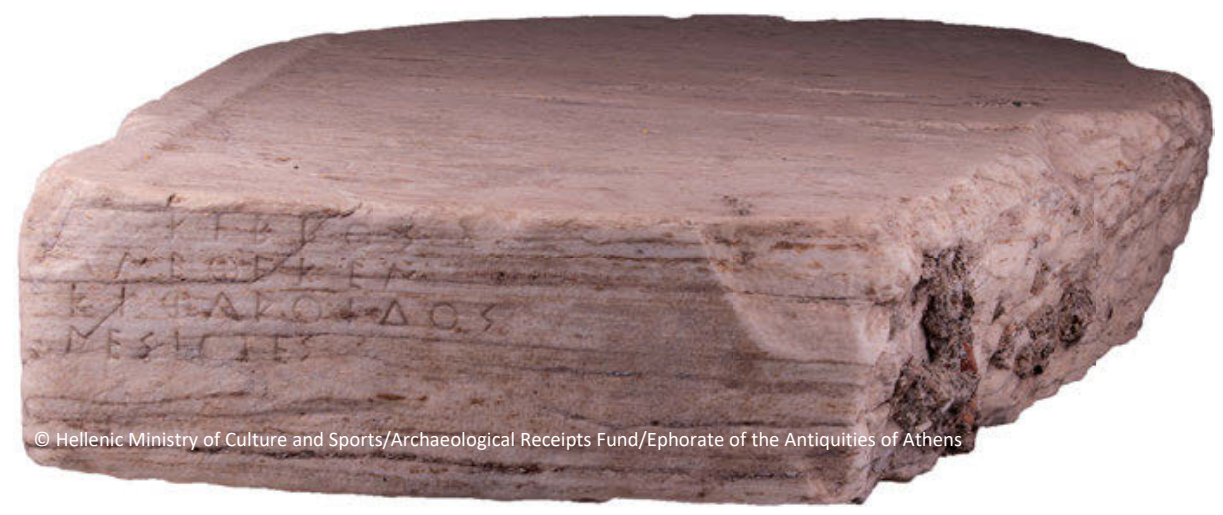

Abb. 2.6: Block von der Stufenbasis des Alkibios, um 510-500 v. Chr. (Athen, Akropolis 13262).

eine der unteren Stufen handeln. Alle erhaltenen Stirnseiten sind mit einer Pickung versehen, die an der horizontalen Oberkante der Frontseite von einem glatten Randschlag gesäumt wird (Abb. 2.6). ${ }^{331}$

An der Front ist auch die in altattischem Alphabet verfasste Weihinschrift angebracht, die unter mehreren Gesichtspunkten bemerkenswert ist: Zum einen hat man sie den Sehgewohnheiten des modernen Betrachters zuwiderlaufend exzentrisch nahezu an den äußersten Rand der intakten linken Seite der Basis gesetzt. Dass für ihre ersten drei, jeweils nur ein Wort umfassenden Zeilen anstelle einer kontinuierlichen Fortführung, die ohne Weiteres möglich gewesen wäre, ein Arrangement in stoichedon-Form gewählt wurde, erklärt sich zweifelsohne aus dem ornamental-dekorativen Reiz dieses Schriftlayouts. Zum anderen - und das ist umso erstaunlicher - bleibt die Inschrift ohne Bezug zur Oberflächengestaltung der Frontseite: Sie steht in einem z. T. mit dem Randschlag kongruenten geglätteten Feld, dessen Umriss allein vom Platzbedarf bestimmt wird. Das erinnert frappant an die zuvor schon besprochene Anlage der Inschriften auf den nach Art eines Werkzolls grob gespitzten Säulenschäften.

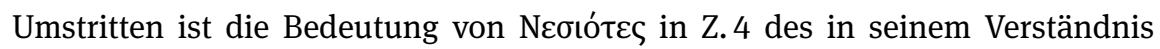
ansonsten unproblematischen Textes. Da für eine Künstlersignatur, mithin für eine Identifikation mit dem Bildhauerkollegen des Kritios, gemeinhin das ergänzende

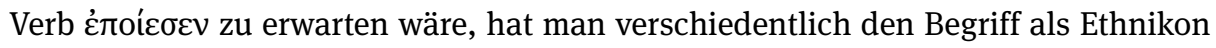
der bei Lesbos gelegenen Insel Nesos aufgefasst. ${ }^{332}$ Die Präsenz eines ionischen Musikers im spätarchaischen Athen wäre jedenfalls wenig verwunderlich: Rhapsodische

331 Raubitschek ad DAA 84 (Zitat auf S.90): ,the vertical faces are carefully picked with the exception of a margin, $c a .0 .004 \mathrm{~m}$. wide, on the upper end of the front face“.

332 Zur Bezeichnung der Bürger von Nesos als nesiotai u. a. Hdt. 1, 151; Diod. 13, 77; Strab. 13, 2, 5. Dementsprechend etwa Jeffery/Lewis ad IG I3 666; Krumeich 2007, 9; Hallof ad DNO I 412. Für eine Identifikation als Künstlersignatur des Nesiotes dagegen: Raubitschek ad DAA 84, wobei Raubitschek eine Deutung als Ethnikon explizit ablehnt; Brunnsåker 1971, 136; Vollkommer-Glökler 2004, 125; Hochscheid 2015, 187 Anm. 128; zögerlich Stewart 2017, 38, $42 f$. 
Agone erfuhren gerade seitens der Peisistratiden eine intensive Förderung, die zu diesem Zweck auch gezielt zeitgenössische ,Stars‘ wie Simonides von Keos oder Anakreon von Teos nach Athen brachten. Und auch nach dem Ende der Tyrannis blieben die städtischen Dionysia ein wichtiger Anziehungspunkt für auswärtige Künstler. ${ }^{333}$ Andererseits erscheint, um auf die Weihinschrift zurückzukommen, nicht nur die Wahl des altattischen Alphabets für einen ionischen Auftraggeber eher ungewöhnlich. ${ }^{334}$ Auch bleibt ein inhaltlicher Bezug auf den vorangehenden Text unbefriedi-

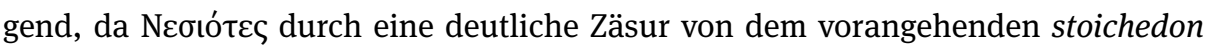
abgesetzt wird. Ohne Zwang fallen in der letzten Zeile nämlich insgesamt acht Buchstaben in die regulären sechs stoichoi. Eine sichere Entscheidung ist in diesem Fall wohl nicht zu treffen, auch wenn das Gestaltungsmotiv der Unfertigkeit tatsächlich auch von der Werkstatt des Kritios und Nesiotes in einigen noch zu besprechenden Fällen aufgegriffen wurde. ${ }^{335}$

Bleiben also bei der Basis des Alkibios die Unfertigkeit signalisierende Oberflächenbearbeitung wie auch die Inschrift voneinander getrennte und deshalb ausschließlich additiv kombinierte Gestaltungselemente, lässt sich an einem einige Jahre jüngeren Stück von der Akropolis eine weitaus homogenere Konzeption beobachten. Von der wohl im frühen 5. Jh. v. Chr. ${ }^{336}$ entstandenen quadratischen Basis (Kat. 2.2) haben sich lediglich Partien ihrer rechten Seite erhalten. In diesem Erhaltungszustand wäre eine Rekonstruktion als kleinformatigere Quaderbasis oder aber als Kapitell einer Pfeilerbasis denkbar, ohne dass sich letztendlich eine sichere Entscheidung treffen ließe. ${ }^{337}$ Etwas klarer ist der Befund in Bezug auf die Frage, was für ein Votiv einstmals auf der Basis stand. Die auf der Oberseite des Blockes erhaltene rechteckige Plinthenbettung spricht für die Ergänzung mit einer Sitzstatue, möglicherweise der Athena. ${ }^{338}$ In der Weihinschrift bleibt der Adressat aber ungenannt.

333 Shapiro 1993; Bundrick 2005, 8f. Zu Simonides von Keos und Anakreon von Teos in Athen: Slings 2000, 60-66.

334 Zum Verhältnis von Bildhauer und Auftraggeber bei archaischen Votiven, insb. mit Blick auf die Wahl von Alphabet und Dialekt in den Weihinschriften: Keesling 2005, 413f.; Kaczko 2010, 210-214. Für diverse Beispiele, bei denen die Weihinschrift mit der Herkunft des Auftraggebers in Zusammenhang gebracht werden kann: Buck 1913, 135-143. Weitaus seltener sind Fälle, bei denen die Herkunft des Künstlers den Ausschlag für die Wahl von Alphabet und Dialekt gab, siehe dazu Kaczko 2010, 214 Anm. 39.

335 Unentschieden in dieser Frage auch Franssen 2011, 213f. Zur Basis der von Kritios und Nesiotes geschaffenen Tyrannenmörder von der Agora siehe hier Anm. 412.

336 Bei der Erstpublikation wurde die Basis von Kreeb 1986, 27 anhand der Buchstabenformen in die Jahre um 490-480 v. Chr. datiert, während sich Jeffery/Lewis ad IG I $\mathrm{I}^{3} 830$ bis für die Datierung „,480470 ?“ entschieden. Dagegen argumentierte Viviers 2002, 66 Anm. 52 mit dem Verweis, dass „une datation aussi basse ne s'impose nullement si l'on prend en compte l'origine chiote du sculpteur", wieder für eine höhere Datierung um die Wende vom 6. zum 5. Jh. v. Chr. In ähnlicher Weise folgte zuletzt Butz 2010, 14 der von Kreeb vorgeschlagenen Datierung.

337 Vgl. Kissas 2000, 283 Nr. C 81. Für eine Rekonstruktion als niedrige Quaderbasis Kreeb 1986, 28; als Deckblock einer Pfeilerbasis dagegen Keesling 2010, 126.

338 Vgl. Kreeb 1986, 28. 


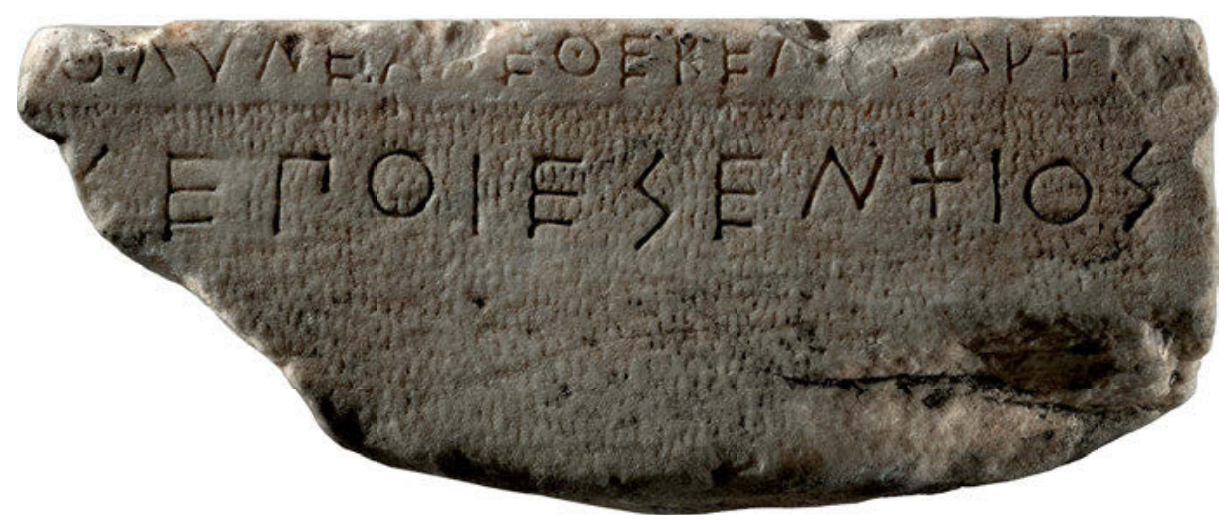

Abb. 2.7: Fragment eines Basisblocks, frühes 5. Jh. v. Chr. (Athen, Akropolis-Museum 13639).

Die erhaltene Front- und rechte Nebenseite zeigen beide die gleiche anathyroseartige Zurichtung mit Randschlag und Spiegel (Abb. 2.7), die mit Blick auf ihre qualitätsvolle Ausarbeitung aber sicherlich nicht für einen tatsächlichen Versatz am Bau konzipiert war. Auf der Frontseite wurde die in altattischem Alphabet verfasste Weihinschrift einer namentlich unbekannten, wohl athenischen Stifterin in den glatten horizontalen Saum eingemeißelt. Auch wenn der Erhaltungszustand eine Beurteilung erschwert, lässt doch der Umstand, dass die Inschrift zumindest auf der rechten Seite bis zur Blockkante reichte, mithin mit einiger Wahrscheinlichkeit über die gesamte Länge des Blockes lief, auf eine eng abgestimmte Konzeption von Text, Schrift und Schriftträger schließen. Zum Zeitpunkt der Beschriftung war die Zurichtung der Stirnseiten jedenfalls bereits abgeschlossen, wie ein Detail der Künstlersignatur zeigt.

Die Signatur des namentlich ebenfalls unbekannten Bildhauers von Chios - er könnte womöglich mit Boupalos oder Athenis identisch sein, deren Vater, der chiotische Künstler Archermos, im späten 6. Jh. v. Chr. auf der Akropolis tätig war ${ }^{339}$ - ist unterhalb der Weihinschrift in den gezahnten Spiegel gesetzt worden. Dabei überschneidet sich das Sigma von Xĩos geringfügig mit dem vertikalen Randschlag, der also bereits ausgearbeitet war. ${ }^{340}$ Auffällig ist, dass der Spiegel im Zuge des Beschreibprozesses anders etwa als bei den grob gespitzten Säulenbasen nicht noch einmal eigens geglättet wurde. Offenbar scheint man die weitaus feinere Zahnung

339 So erstmals Kreeb 1986, 28. Ebenso Viviers 2002, 66f., der die Buchstaben mit DAA $9=I G \mathrm{I}^{3} 756$ (um 500-480 v. Chr.) vergleicht, dem Werk eines weiteren namentlich unbekannten chiotischen Bildhauers. Vgl. Kaczko 2016, 109f.; Hallof/Kansteiner/Lehmann ad DNO I 201-209 (S. 127), die in beiden Fällen gleichermaßen auf die mögliche Identifikation mit Boupalos hinweisen. Zu der von Archermos geschaffenen Säulenbasis der Iphidike: DAA 3 = IG I³ 683 (um 510-500 v. Chr.); vgl. Kaczko 2010; Kaczko 2016, 100-111 Nr. 21; DNO I 200. Dagegen wollte Hochscheid 2015, 185 in ihm einen gleichnamigen Enkel erkennen. Allgemein siehe auch Vollkommer 2001, 76f. (Archermos); Bröker 2001, $104 \mathrm{f}$. (Athenis); Müller 2001, 125f. (Boupalos).

340 Hier täuscht die von Kreeb 1986, 26 Abb. ohne Nr. publizierte Zeichnung des Blockes. 
als hinreichenden Schreibgrund erachtet zu haben. ${ }^{341}$ Höchst ungewöhnlich, wenngleich nicht völlig singulär, ist die Größe der Künstlersignatur (2,1-2,6 cm), welche die Weihinschrift (1,3-1,5 cm) deutlich übertrifft. ${ }^{342}$ Im vorliegenden Fall mag dieser Umstand zwei Aspekten geschuldet gewesen sein, die allerdings nicht voneinander getrennt betrachtet werden können, nämlich der Gewährleistung von Lesbarkeit sowie der Prominenz des Künstlers, der das Prestige von Votiv und Dedikanten umso mehr steigerte. ${ }^{343}$ In jedem Fall förderten der Kontrast von glattem und rauhem Schreibgrund sowie die unterschiedliche Schriftgröße eine visuelle Differenzierung von Weihinschrift und Künstlersignatur, wie sie an archaischen und klassischen Statuenbasen vielfach beobachtet werden kann. ${ }^{344}$

Mit dem wiederum von der Akropolis stammenden Weihgeschenk des Kallias (Kat. 2.4), des Sohnes des Hipponikos, tritt abermals ein prominentes Mitglied der städtischen Eliten Athens in den Fokus, wobei das Anathem mit einer Datierung in die Zeit um 480 v. Chr. in die jüngeren Jahre des Staatsmannes fällt. ${ }^{345}$ Während die Stirnseiten der Quaderbasis anathyroseartig bearbeitet sind, zeigt ihre Oberseite vier Zapflöcher, anhand derer sich eine wohl leicht überlebensgroße Bronzestatue mit ruhigem, zurückhaltend ponderierten Standmotiv rekonstruieren lässt (Abb.2.8). $\mathrm{Ob}$ es sich vielleicht um den offenbar dreifachen Olympioniken selbst handelt, der im aristokratischen Habitus seine Pferdegespanne in Olympia an den Start gehen ließ, ist in der Forschung umstritten. ${ }^{346}$ So führt denn auch das knappe Formu-

341 So wie nämlich auch auf den zahlreichen unkannelierten spätarchaischen Säulenbasen, siehe hier Anm.312. Wenn hingegen bei der Anbringung einer sekundären Inschrift am Kenotaph mit den sog. „Marathon-Epigrammen“ (siehe hier Anm.417) eine zusätzliche Glättung des Schreibgrundes erfolgte, dürfte das auf die gröbere Bearbeitung des gespitzten Spiegels der Basisblöcke zurückzuführen sein. Ähnliches gilt auch für die Beschriftung einer Basis aus der zweiten Hälfte des 5. Jhs. v. Chr. (Kat. 2.8). 342 Vgl. Kreeb 1986, 27 mit Anm. 5. Vergleichbar ist die Künstlersignatur des Philergos am Grabmonument des Leanax (IG I3 1365 = DNO I 378; Viviers 1992, 108 Abb. 18; Kissas 2000, 61f. Nr. A 28) oder aber die Künstlersignatur des Euphron an der Pfeilerbasis Kat. 2.12.

343 Vgl. Kreeb 1986, 27 Anm.6. Zum Prestigegewinn durch Künstlerinschriften: Viviers 2006, bes. 150-154; Hurwit 2015, 142f. Unter vergleichbaren Vorzeichen von Lesbarkeit und Prestige steht außerdem ein wohl kurz nach 480 v. Chr. entstandenes Beuteanathem aus der Zeit der Perserkriege, das sich

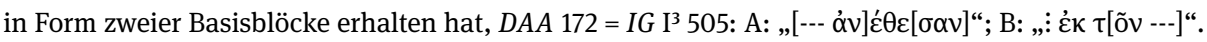
Die allseitig anathyroseartig bearbeiteten Blöcke trugen freilich nicht die Athena Promachos des Pheidias, wie in der älteren Forschung vermutet wurde, so etwa Raubitschek/Stevens 1946; Raubitschek ad DAA 172. Dagegen u. a. Thompson 1965, 318 Anm. 4; Dinsmoor 1967-1968, 151-155 (Taue der Hellespontbrücken); Gauer 1968, 72f. (Schiffsanathem); Lundgreen 1997, 191 mit Anm. 10 zur Datierung auf Grundlage der Epigraphik. Die Weihinschrift ist ohne weitere Glättung in den gespitzten Spiegel gesetzt worden, was neben der Monumentalität des Anathems per se ein Grund für die ungewöhnliche Buchstabenhöhe von rund $10 \mathrm{~cm}$ sein dürfte.

344 Vgl. Keesling 2003, 34; DNO I, XXIX; Hurwit 2015, 121-131, 142f. Siehe dazu oben Kapitel I, S. 55-62. 345 Zu Kallias: Plut. Aristeides 5; 25,6. Vgl. RE X,2 (1919) 1615-1618 s. v. Kallias (2) (H. Swoboda); Moretti 1957, Nr.164, 169, 176; Davies 1971, 254-270 Nr. 7826 (V.); Kyle 1987, 203 f. A 31.

346 Für eine derartige Deutung: Raubitschek ad DAA 111; vorsichtiger Keesling 2003, 67, 170f. Zu den olympischen Siegen des Kallias: Schol. Aristoph. Nub. 64; vgl. aber Davies 1971, 258; Kyle 1987, 


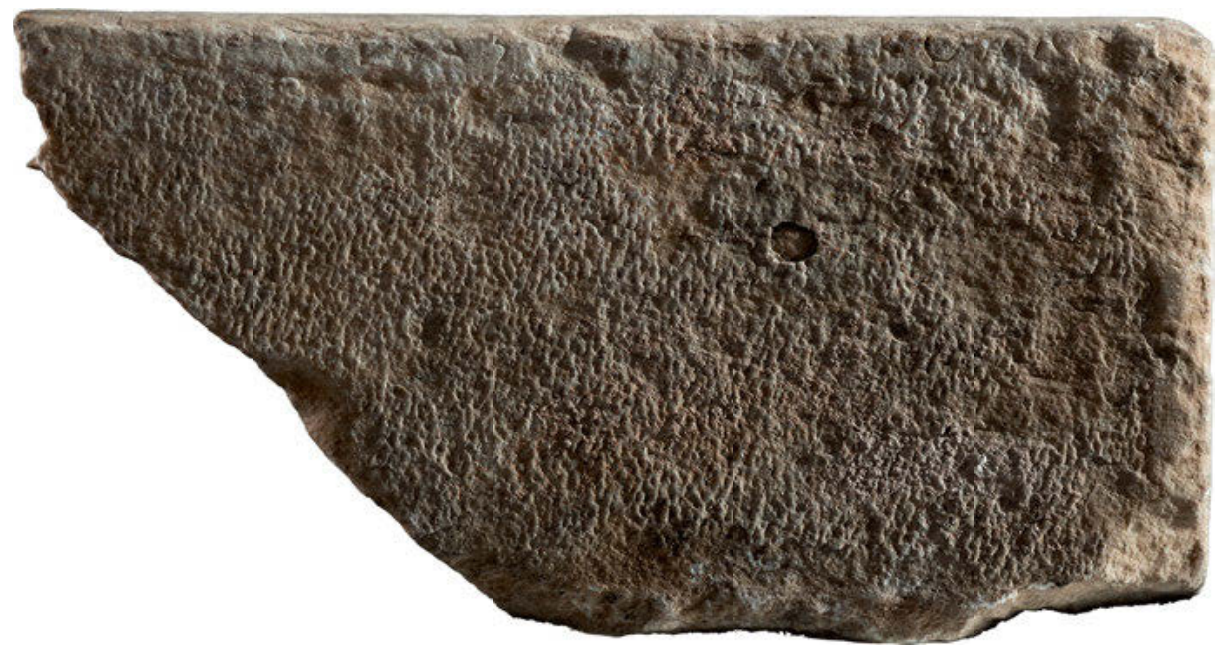

Abb. 2.8a: Basisblock des Kallias, um 480 v. Chr. (Athen, Akropolis-Museum 7898).
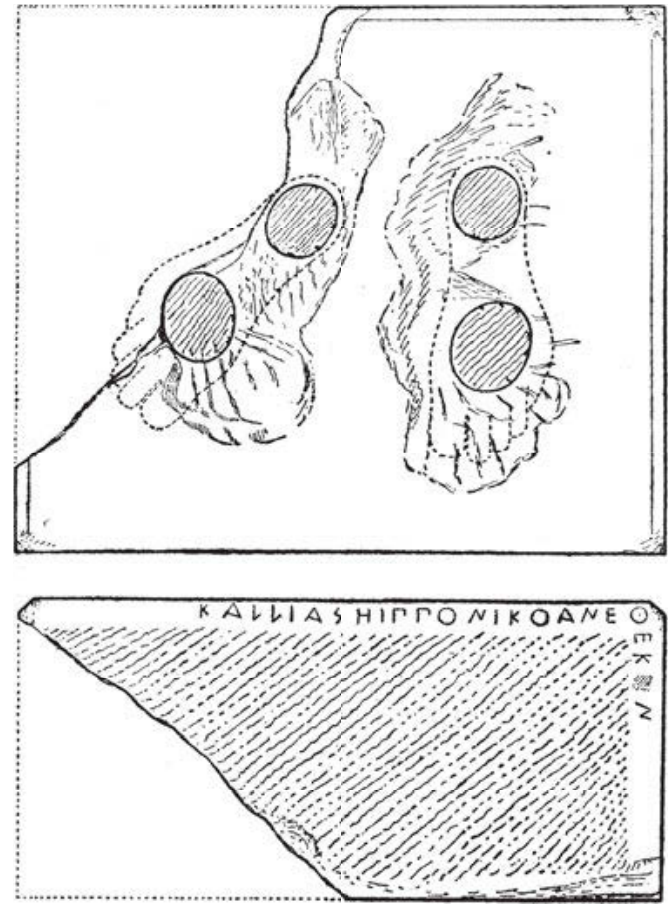

Abb. 2.8b: Zeichnung der Kallias-Basis nach F. Studniczka.

203f. A 31, der an der älteren Deutung des Weihgeschenks als Athena festhält. Allgemein zu archaischen Siegerweihungen bzw. Athletendarstellungen auf der Akropolis: Keesling 2003, 170-175; Franssen 2011, 285-290. 
lar der Weihinschrift in dieser Frage nicht weiter. Bemerkenswert ist hingegen ihre Platzierung auf dem abgeschrägten Randschlag der Frontseite. ${ }^{347}$ Denn entgegen der üblichen Praxis beginnt sie nicht an der linken Außenkante, vielmehr stehen der Name und das Patronymikon des Kallias - und das ist für die Zeit durchaus exzeptionell - im Zentrum der Basis, so dass sie gleichsam einer Beischrift axial mit der Hauptansichtsseite der auf diese Weise ,benannten' Statue korrespondieren. ${ }^{348}$ Bedingt durch diese Position mussten die letzten vier Buchstaben aus Platzmangel vertikal auf den Randschlag der rechten Außenkante angebracht werden. Inwieweit man diesen Umstand absichtsvoll miteinplante, so dass die Inschrift sowohl horizontal wie vertikal einen Teil des Randschlages einnahm, oder lediglich als Zugeständnis in Kauf nahm, lässt sich nicht stichhaltig beantworten. ${ }^{349}$ Eine vergleichbare graphische Konzeption des Geschriebenen, das nach Art eines Ornamentbandes die Außenkanten des Trägers schmückt, findet sich aber verschiedentlich in der archaischen Inschriftenkultur. ${ }^{350}$ Dass es sich bei dem vorliegenden Fall um einen gezielten Rückgriff handelt, sei es als Schmuckform, sei es zum Zweck der Repräsentation, der den Kontrast zum fortschrittlichen Stil der ponderierten Statue umso prägnanter hervorhebt, erscheint durchaus bedenkenswert. ${ }^{351}$

Wie bereits erwähnt, nahmen in den Jahren nach den Perserkriegen auch die beiden durch ihr Hauptwerk der Tyrannenmörder berühmten Bildhauer Kritios und Nesiotes die dekorative Unfertigkeit als Motiv der Oberflächengestaltung für private Weihgeschenke auf. ${ }^{352}$ Der Erhaltungszustand einer um 475-465 v. Chr. datierten

347 Für eine vergleichbare Abschrägung der Blockkanten an einer Statuenbasis siehe $D A A 88=I G \mathrm{I}^{3}$ 665 (Ende des 6. Jhs. v. Chr.); vgl. Kissas 2000, 263 Nr. C 33.

348 Ausführlicher zu dieser speziellen Frage wie auch zum Statuenmonument des Kallias insgesamt wird sich der Verf. demnächst an anderer Stelle äußern, siehe dazu Fouquet, Johannes (in Vorbereitung), „Money, Fame, Aesthetics: The Statue Monument of Kallias and Elite Self-representation in Early Classical Athens“, in: Rachel Nouet (Hg.), Tagungsband „Bases en contextes“ (École française d'Athènes, Athen, 24.-25.06.2019). Eine derartige Platzierung ist jedenfalls an zeitgenössischen Statuenbasen höchst exzeptionell, sieht man von Fällen ab, bei denen wie am Basisblock des Aristodikos lediglich ein einzelner Name angebracht war, siehe dazu $I G \mathrm{I}^{3}$ 1244; Kissas 2000, $68 \mathrm{Nr}$. A 39. Sie findet sich hingegen an jüngeren Monumenten wie beispielsweise an der Basis der Philoumene (nach der Mitte des 4. Jhs. v. Chr.), siehe dazu SEG 44, 136; DNO III 1843.

349 Die weite Sperrung von ávé $\theta \varepsilon \kappa[\varepsilon] v$, wie sie von der von Raubitschek ad DAA 111 publizierten Zeichnung suggeriert wird, ist am Stein selbst nicht nachvollziehbar. Der Buchstabenabstand, wie er von der hier abgebildete Zeichnung von Franz Studniczka (Abb. 2.8b) wiedergegeben wird, entspricht, soweit erhalten, dem tatsächlichen Befund.

350 Exemplarisch etwa drei Horoi von der Athener Agora: Lalonde 1991, 27 Nr. H $25-27$ mit Taf. 2 (um 500 v. Chr.). Vgl. IG XII 9, 297 (Jeffery 1961, Taf. 6, 13); IG IV 801 (Jeffery 1961, Taf. 32, 2); IG IV 1, 141 (Jeffery 1962, Taf. 34, 12); IG IX 1, 869 (McGowan 1995, 616 Abb.1); IvO 154.

$351 \mathrm{Zu}$ den archaisierenden Tendenzen in der attischen Plastik des 5. Jhs. v. Chr.: Brahms 1994; vgl. zuletzt Elsner 2017.

352 Allgemein zu Kritios und Nesiotes: Rumpf 1964; Brunnsåker 1971; Vollkommer-Glökler 2004, 125; Krumeich 2007; Stewart 2008. Vgl. DNO I 557-570. Zur Basis der Tyrannenmörder siehe hier Anm. 412. 


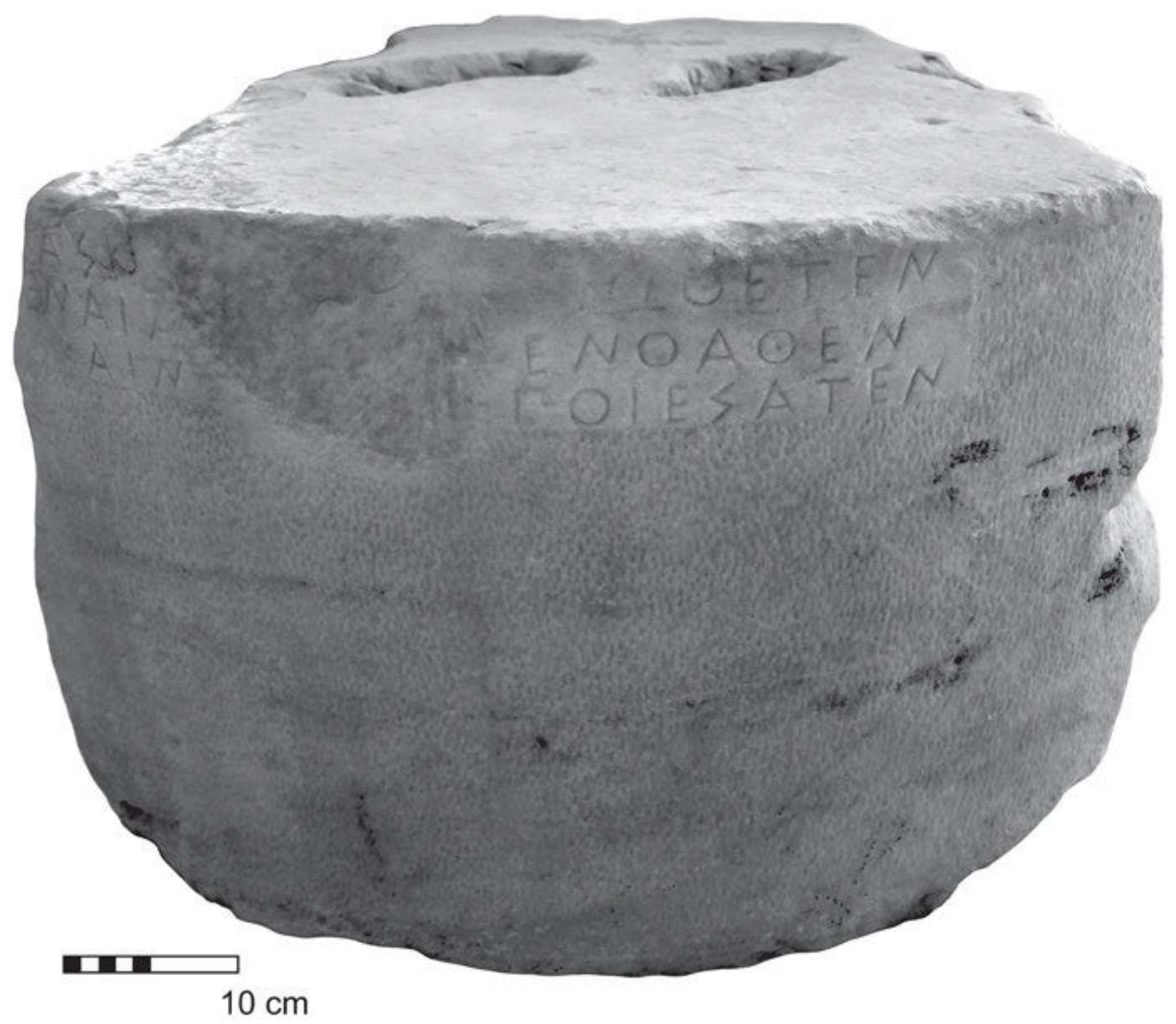

Abb. 2.9: Rundbasis des [---]as und des Opsios, um 480-470 v. Chr. (Athen, Akropolis-Museum 13270).

achtseitigen Basis (Kat. 2.10), ${ }^{353}$ auf deren konischer Oberfläche zwei glatte, mit Weihinschrift und Künstlersignatur beschriftete Bänder sowie ein weiteres, fein gespitztes Band konzentrisch alternieren, sowie eine wohl zeitgenössische Quaderbasis mit stehengelassener Hebebosse $\mathrm{e}^{354}$ ist zu schlecht für eine Beurteilung. Demgegenüber hervorzuheben ist eine Rundbasis aus pentelischem Marmor (Kat. 2.9). Sie wurde von zwei athenischen Bürgern aus dem Demos Oa, von denen sich nur Opsios namentlich erhalten hat, in den Jahren um 480-470 v. Chr. auf der Akropolis der Athena geweiht (Abb. 2.9). ${ }^{355}$ Anhand zweier Zapflöcher auf der Oberseite des Blockes lässt sich eine

353 Für eine Datierung vor 480 v. Chr.: Raubitschek ad DAA 161 und DAA 161a; Kissas 2000, 106f. Nr. B 33. Dass eines der Fragmente im sog. ,Perserschutt‘ auf der Akropolis gefunden wurde, ist als Argument für diesen zeitlichen Ansatz aber durch die neueren Untersuchungen von Stewart 2008 als obsolet zu erachten. Das zweite Basisfragment stammt von der Agora. Für eine jüngere Datierung bereits Jeffery/Lewis ad IG I3 846; so auch DNO I 568. Geagan 2011, 14 Nr. A22 „,before mid-5th century“.

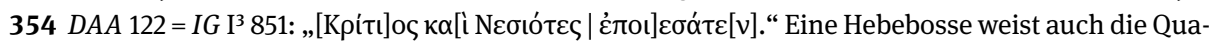
derbasis Kat. 2.6 auf ihrer Rückseite auf.

355 In der Basis wollte man verschiedentlich in der älteren Forschung eine wiederverwendete Säulen- 
lebensgroße Bronzestatue in vermutlich leicht ponderiertem Stand rekonstruieren, die sich mit ihrer Linken auf eine Lanze stützt. Dass es sich dabei nicht etwa um einen männlichen Gerüsteten, sondern vielmehr um die bewaffnete Göttin selbst handelt, die motivisch etwa mit der zeitgenössisch entstandenen Athena des Angelitos verglichen werden kann, macht nicht zuletzt die Zahl der Dedikanten wahrscheinlich. ${ }^{356}$

An der Stirn des Blockes fassen allseitig zwei glatt gearbeitete horizontale Randschläge an der Ober- und Unterkante einen äußerst fein gezahnten Spiegel ein, wodurch der Eindruck einer anathyroseartigen Bearbeitung entsteht. In dieser Gestaltungsweise gleicht er einer zylindrischen Statuenbasis aus Olympia, bei der die Inschrift wiederum auf den geglätteten Saum am oberen Basisrand gesetzt wurde. Das von Sparta um 490 v. Chr. gestiftete Weihgeschenk ist zugleich ein seltenes Beispiel für die Verbreitung dieser spezifischen Oberflächengestaltung an zeitgenössischen statuarischen Monumenten über die Grenzen von Athen hinaus. ${ }^{357}$ Durch die Wahl der Basisform wird indes - und das offenbar bewusst - in beiden Fällen das ambivalente Zusammenspiel von bautechnisch-funktional begründeter Praxis und dekorativer Schmuckform durchbrochen.

Diese im Grunde schon an der Kallias-Basis (Kat. 2.4) mit dem abgeschrägten Randschlag fassbare Tendenz lässt sich auch an zwei weiteren Votivträgern von der Akropolis beobachten. Es handelt sich zum einen um eine Pfeilerbasis (Kat. 2.11), die ein gewisser Euthydikos samt Marmorstatue - von ihr zeugt nur noch die kurvierte Plinthenbettung auf der Oberseite des Abakus - wohl bald nach 480 v. Chr. weihte. ${ }^{358}$ Ohne überhaupt ein für den Versatz bestimmtes Architekturglied im weiteren Sinne zu sein, werden die Front- und Nebenseiten des Pfeilerschaftes trotz allem von einer bis in die Kehlung zwischen Schaft und Abakus reichenden, inzwischen hinlänglich bekannten anathyroseartigen Bearbeitung aus glattem Randschlag und gespitztem Spiegel verziert, die sich zudem auch auf den Nebenseiten des Abakus wiederfindet. Demgegenüber wurde die Frontseite mit der kurzen zweizeiligen Weihinschrift in

trommel des von den Persern zerstörten Vorparthenon erkennen, so etwa Raubitschek ad DAA 160; Rumpf 1964, 144. Das scheitert indes an den Abmessungen, wie Kalpaxis 1986, 123 überzeugend dargelegt hat. Zur Identifikation des Opsios als Stifter weiterer Weihgeschenke auf der Akropolis: Franssen 2011, 214 mit Anm. 590.

356 Keesling 2000, bes. 70-72 für eine Identifikation als Athena; so bereits Raubitschek ad DAA 160, freilich ohne nähere Begründung. Zur Athena des Angelitos siehe auch Brouskari 1974, 129f. Nr. 140 mit Abb. 248; Kissas 2000, 219-221 Nr. B 172; Kaczko 2016, 298-303 Nr. 77.

357 IvO 252 = IG V 1, 1562 = CEG I 367. Vgl. Dillon 1995 (mit Lit.); Keesling 2010, 114f. Für zeitgenössische Vergleichsbeispiele aus Delphi mit anathyroseartiger Bearbeitung siehe etwa FD III,4 452; 454.

358 Nach Raubitschek ad DAA 294 könnte es sich um ein zweites Votiv des namensgebenden Stifters der Euthydikos-Kore handeln, siehe dazu DAA $56=I G I^{3}$ 758; Kissas 2000, 207 Nr. B 163. Vgl. Franssen 2011, 256 Anm. 894. Es sei allerdings auf den Umstand verwiesen, dass die Weihinschrift der Euthydikos-Kore in altattischem Alphabet verfasst wurde, die hier in Rede stehende hingegen im ionischen Alphabet. Zur Wahl von Schrift und Dialekt auf archaischen statuarischen Monumenten seitens des Auftraggebers siehe hier Anm. 334. 


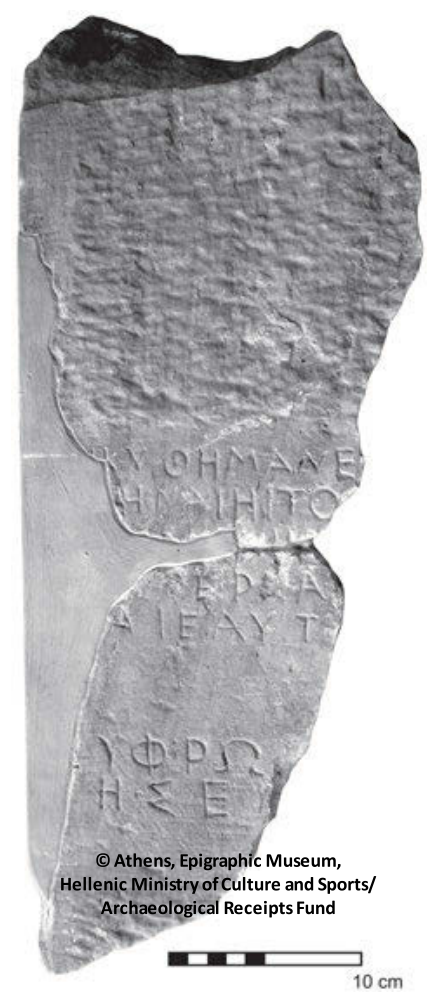

Abb. 2.10: Schaftfragment von der Pfeilerbasis der Mikythe, um 470-450 v. Chr. (Athen, Epigraphisches Museum 6254).

stoichedon ausschließlich geglättet. In ihrer dezentralen, dicht an den Außenkanten orientierten Platzierung erinnert sie beispielsweise an das Layout der Alkibios-Basis (Kat. 2.1).

Eine zweite Pfeilerbasis (Kat. 2.12), die das um 470-450 v. Chr. von dem parischen Künstler Euphron angefertigte Weihgeschenk der Mikythe an Athena trug, ist nur fragmentarisch erhalten (Abb. 2.10). ${ }^{359}$ Auf Grund der geringen Stärke des Schaftes von lediglich $6 \mathrm{~cm}$ ist anzunehmen, das den Pfeiler einst ein Relief bekrönte. Die Front- und beide schmalen Nebenseiten des Schaftes sind wiederum anathyroseartig zugerichtet worden. Bemerkenswerterweise wird der gespitzte Spiegel der Frontseite von einem geglätteten Feld zweigeteilt. Hier hat man die metrische Weihinschrift der Stifterin Mikythe, die nach Schrift und Dialekt wahrscheinlich aus Ionien stammte, sowie mit etwas Abstand die abermals in größeren Buchstaben angelegte Künstlersignatur des Euphron eingemeißelt. ${ }^{360}$ Wird durch diese spezifische Gestaltung die vermeintliche bautechnische Zweckgebundenheit ad absurdum geführt, lässt sich doch ein enger konzeptioneller Zusammenhang zwischen Geschriebenem und Dekor

359 Zu Euphron: Walter-Karydi 2001b, 230f.; DNO I 657-660.

360 Zur Forschungsdiskussion um die ionische bzw. attische Identität der Mikythe siehe zusammenfassend Kaczko 2016, 355-357 (mit Lit.). 
feststellen. Die einzelnen Inschriftenzeilen orientieren sich nämlich, sollte das von A. Raubitschek rekonstruierte Layout zutreffend sein, mehr oder weniger an der Breite des Randschlages. ${ }^{361}$

Ähnliches gilt, um nach diesem Exkurs auf die von Kritios und Nesiotes geschaffene Rundbasis zurückzukommen, auch für die noch nicht näher besprochene Inschrift (Abb.2.9): Sie wurde mit der Hauptansichtsseite der Statue zusammenfallend, in einem dreizeiligen stoichedon-Format an der Oberkante des Blockes plaziert. Um ausreichenden Schreibgrund zu gewährleisten, verbreiterte man dafür den zu schmalen Randschlag im Bereich der Inschrift. Einmal mehr löst sich hier also der Dekor von seiner ursprünglichen bautechnischen Zweckgebundenheit. Dabei umfassen die ersten beiden Zeilen die eigentliche Weihinschrift, die letzte Zeile dagegen die Künstlersignatur, deren einzelne Buchstaben sich teilweise bis aufs engste an der Unterkante des Randschlages orientieren. Nicht sicher entscheiden lässt sich freilich, ob beide Inschriften erst nach der abgeschlossenen Oberflächenbearbeitung eingemeißelt wurden, was ein höheres Maß an Planung voraussetzt, oder aber - und das scheint die praktikablere Lösung zu sein - angebracht wurden, ehe man den Spiegel gewissermaßen nach Bedarf spitzte und auf diese Weise den glatten Randschlag herauspräparierte. Beschnittene Buchstabenhasten, die für einen derartigen Fertigungsprozess ein sicheres Indiz bieten würden, lassen sich allerdings nicht nachweisen.

Eindeutig nachvollziehbar ist das hingegen im Falle der Leagros-Basis (Kat. 2.5), die als einzige der hier besprochenen statuarischen Monumente zweifelsfrei von der Athener Agora stammt. ${ }^{362}$ In den Jahren nach 480 v. Chr. wurde sie gegen die Westseite des Peribolos des Zwölf-Götter-Altars am Nordrand der Agora errichtet. ${ }^{363}$ Die Einlassungsspuren auf der Oberseite der Basis lassen ähnlich wie im Falle der Kallias-Basis die Rekonstruktion einer Bronzestatue mit ponderiertem Standmotiv zu. Dass es sich um eine Athletenstatue handelt, könnte die enge Beziehung des ZwölfGötter-Kultes mit athletischen Agonen erhärten. ${ }^{364}$ Allseitig hat die Basis mit einem $\Pi$-förmigen Randschlag und gespitzten Spiegel eine anathyroseartige Zurichtung erfahren (Abb. 2.11). Eng orientiert an den Blockgrenzen, hat man dabei die zweizeilige

361 Raubitschek ad DAA 298 mit Abb.

362 Von der Agora bzw. dem Tempel des Apollon Patroos könnte vielleicht darüber hinaus auch die dem Apollon geweihte Orthostatenbasis Kat. 2.3 stammen, die als Spolie in der hellenistischen Brüstung der Klepsydra am Nordabhang der Akropolis wiederverwendet wurde.

363 Eine Datierung nach 480 v. Chr. entspricht der gegenwärtigen communis opinio, so etwa Gadbery 1992; Seaman 2002, 108; Geagan 2011, 9f. A9. Dagegen wollte Raubitschek 1939a, 160-164 die LeagrosBasis zeitlich vor 480 v. Chr. ansetzen; darin u. a. gefolgt von Kyle 1987, 222f. P 100. Wie Gadbery 1992, bes. 474 im Rahmen ihrer Neuuntersuchung des Zwölf-Götter-Altars zeigen konnte, gibt es dafür aber keinerlei positive stratigraphische Indizien. Allgemein zu Athletenstatuen auf der Athener Agora: Seaman 2002.

$364 \mathrm{Zu}$ dieser Konnotation des Zwölf-Götter-Altares: Raubitschek 1939a, 160f.; Seaman 2002, 107 Anm. 29 (mit Lit.). Gegen eine Identifikation als Athletenbildnis dagegen Krumeich 1997, 64-68. 


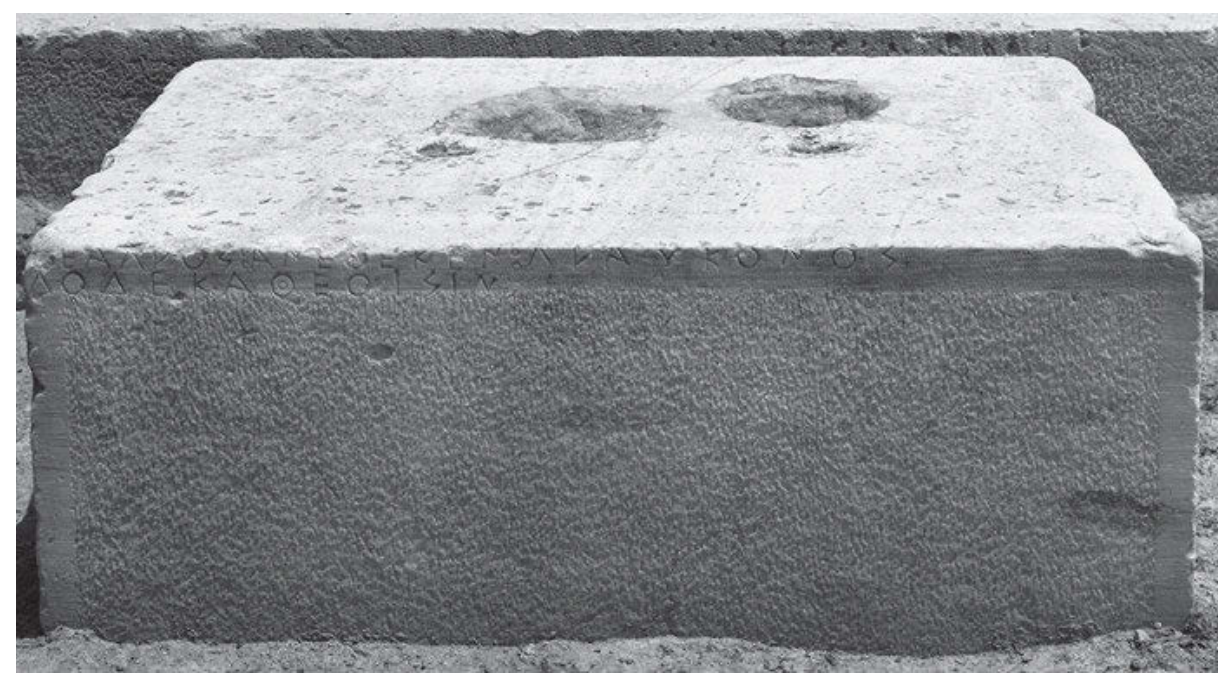

Abb. 2.11: Basisblock des Leagros, nach 480 v. Chr. (Athen, Agora I 1597).

Weihinschrift des Leagros, der einer Familie der sozialen Führungsgruppe Athens entstammte, in typischer Weise im horizontal verlaufenden Randschlag an der Oberkante der Frontseite angebracht. ${ }^{365}$ Der Umstand, dass sich die Buchstaben der zweiten Zeile z. T. mit dem Spiegel überschneiden, legt nicht nur das Verhältnis von Oberflächengestaltung und Beschriftung im Fertigungsprozess der Basis offen, sondern zeigt auch, dass der Randschlag zumindest im vorliegenden Fall eben nicht im Sinne einer Rahmung konzeptualisiert war, sondern vornehmlich als günstiger Schreibgrund zur Verfügung stand.

An die zuvor diskutierten Beispiele von dekorativer Unfertigkeit lassen sich weitere statuarische Monumente von der Akropolis anschließen. Diese Quaderbasen (Kat. 2.6-7, 2.21-22, 2.24), deren Stirnseiten, soweit erkennbar, mit Randschlag und Spiegel bearbeitet waren, sollen hier nicht im Einzelnen besprochen werden. Es sei deshalb nur auf einige Details hingewiesen. So wurde etwa an der um 475 v. Chr. entstandenen Basis Kat. 2.6 mit einer auf dem gespitzten Spiegel angebrachten Hebebosse ihre ,Unfertigkeit‘ durch ein zusätzliches Schmuckelement pointiert hervorgehoben. ${ }^{366}$

Bei dem jüngsten, wohl um 440 v. Chr. entstandenen Monument (Kat. 2.22) handelt es sich um die Weihung des ansonsten unbekannten, wohl ionischstämmigen Pyres, der den kretischen Bildhauer Kresilas als ausführenden Künstler engagierte

365 Zur sozialen Herkunft des Leagros: Davies 1971, 90-92 Nr. 3027; Kyle 1987, 222f. P 100.

366 Raubitschek ad DAA 119 vermutete auf Grund der ähnlichen Buchstabenformen, dass die Basis aus der Bildhauerwerkstatt von Kritios und Nesiotes stammen könnte. Es war aber durchaus üblich, dass die auf das Einmeißeln von Inschriften spezialisierten Steinmetze für mehrere Werkstätten arbeiten, siehe hier Anm. 381. 


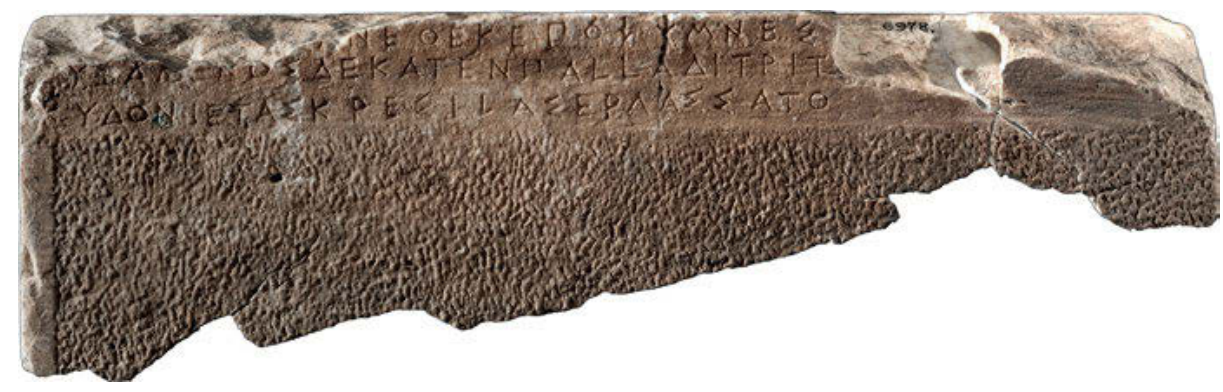

Abb. 2.12: Basisblock des Pyres, um 440 v. Chr (Athen, Akropolis-Museum 6978).

(Abb. 2.12) ${ }^{367}$ Der erhaltene Block, der sicherlich zu einer in dieser Zeit bereits eher ungewöhnlichen Stufenbasis ergänzt werden muss, ist, was seine Verwendungsgeschichte anbelangt, höchst bemerkenswert. ${ }^{368}$ Die ursprüngliche Konzeption seiner Frontseite sah einen umlaufenden Randschlag vor, wie er sich auch auf der linken Nebenseite erhalten hat. ${ }^{369}$ In diesen Dimensionen bot er aber für das Weihepigramm des Pyres und die Künstlerinschrift des Kresilas nicht genug Schreibgrund, weshalb man einen Teil des bereits gespitzten Spiegels glättete. ${ }^{370}$ Dieser Umstand erinnert frappant an das etwa gleichzeitig entstandene, ebenfalls von der Akropolis stammende Basisfragment Kat. 2.8. Hier wurde der bereits gespitzte Spiegel zum Zweck der Anbringung einer Inschrift noch einmal rudimentär mit dem Zahneisen geglättet, während der Randschlag, soweit erkennbar, unbeschriftet blieb.

Kann damit anhand dieser beiden Stücke nun doch einmal die Wiederverwendung von älteren Baugliedern wahrscheinlich gemacht werden? Eine abschließende Antwort auf diese Frage lässt sich schwerlich finden, zumindest lässt aber die flache Ausarbeitung an beiden Stücken daran zweifeln, dass ihre Stirnseiten tatsächlich als Stoßfugen im Versatz vorgesehen waren. Gerade im Falle der Pyres-Basis könnte man

367 Zur ionischen Herkunft des Pyres, die sich auch im Dialekt der Inschrift widerspiegelt: DNO II 1097; vgl. Kaczko 2016, 377f., 380-382. Zu Kresilas: Weber 2001, 427-431; DNO II 1088-1101.

368 Zur Rekonstruktion als Stufenbasis: Korres 1994, 90 MB 12, wofür die flache, rechteckige oder quadratische Bettung auf der Oberseite des Blockes spricht. Die von Despinis 2008, 293f. vorgeschlagene Rekonstruktion mit einer profilierten Bekrönung vermag dagegen nicht überzeugen, zumal die nah an der Oberkante des Blockes angebrachte erste Zeile der Inschrift bereits durch ein geringfügig ausladendes Profil verdeckt würde. Zum Typus der Stufenbasis in der zweiten Hälfte des 5. Jhs. v. Chr.: Jacob-Felsch 1969, 51f.

369 Bei der spätantiken Wiederverwendung des Blockes in der Westtür des Parthenon wurde ein Teil seiner rechten Partie abgearbeitet, vgl. Korres 1994, 63-67, 90 MB 12. Dafür spricht zum einen das Fehlen eines korrespondierenden vertikalen Randschlages an der rechten Außenkante der Frontseite, zum anderen aber auch, dass die Bettung auf der Oberseite des Blockes wiederum an der rechten Außenkante unvermittelt endet.

370 Bereits erkannt von Raubitschek ad DAA 133 (Zitat auf S.144f.): „the other two lines [nämlich die Z. 2-3] are engraved on a smoothed area which is deeper than the margins and the rest of the roughly picked face; we assume that this area was originally roughly picked“. Diese sekundäre Glättung erfolgte allerdings nicht über die gesamte Blockbreite. 
deshalb vielleicht eher an eine konzeptionelle Änderung des Inschriftenlayouts denken, welche die Nachbearbeitung notwendig machte. ${ }^{371}$ Das bleibt aber Spekulation.

\section{Zwischenfazit: Unfertiges, Geschriebenes, Bilder}

Es lässt sich damit festhalten: Ein wesentlicher Reiz der dekorativen Unfertigkeit dürfte gerade die Variabilität der ansonsten üblicherweise homogenen Oberflächengestaltung der Statuenbasen dargestellt haben. Das ästhetische bzw. funktionale Problem, wo auf den gespitzten oder gepickten Flächen nun die Inschriften anzubringen waren, die man sonst eher auf geglätteten Flächen platzierte, löste man entweder durch die Vergrößerung der einzelnen Buchstaben, häufiger durch eine vorbereitende Glättung des Schriftgrundes oder aber durch die Wahl eines Dekors, der wie die anathyroseartige Zurichtung ohnehin glatte Flächen zum Beschriften bot. Die Verbreiterung des zu beschriftenden Randschlages über die Dimensionen seiner Pendants hinaus stellte in dieser Hinsicht eine naheliegende Möglichkeit dar. Kongruent mit der Oberflächengestaltung verhält sich das Geschriebene dabei ,trägergemäß‘: An den Säulenbasen verlaufen die Inschriften in Übereinstimmung mit der tektonischen Natur ihrer Träger üblicherweise vertikal ${ }^{372}$, während an den Blockbasen mit anathyroseartiger Bearbeitung stets der horizontale Randschlag als Schreibgrund diente.

Überraschend für den modernen Betrachter ist, dass die geglättete Fläche des Randschlages, die per se den Eindruck einer visuellen Rahmung vermittelt, genau zu diesem Zweck in aller Regel - die Kallias-Basis (Kat. 2.4) mit ihrer unter der Statue zentrierten Weihinschrift stellt eine Ausnahme dar - aber ungenutzt blieb, da der Rahmen selbst beschrieben wurde und nicht das durch den Rahmen entstandene Feld: Beschriftet wurde im Sinne der archaisch-klassischen Schriftkultur also kein autonomer Schriftgrund, sondern das Monument an sich im Rahmen der von seiner Oberflächengestaltung angebotenen Möglichkeiten. Der sich in dieser Praxis offenbarende Umstand einer Nachzeitigkeit des Geschriebenen ${ }^{373}$ erhält unter dem Gesichtspunkt der dekorativen Unfertigkeit eine zusätzliche Bedeutungsebene, insofern sie dem Monument, das sich theoretisch noch im Zwischenstadium des Fertigungsprozesses befindet, einem aufgedrückten Siegel gleich seinen finalen Charakter bescheinigt.

371 Denkbar wäre beispielsweise, dass nach der ursprünglichen Konzeption lediglich die Künstlersignatur des Kresilas auf den Randschlag der Basis gesetzt werden sollte, während die Weihinschrift für einen anderen Block der Stufenbasis vorgesehen war. Der Nachweis einer derartigen Anbringungsweise steht freilich aus, was aber nicht zuletzt auch der überwiegend problematischen Überlieferungslage der Stufenbasen geschuldet sein mag. Zur Praxis des Beschreibens von Stufenbasen siehe oben Kapitel I, S.36f.

372 Die horizontale Anbringung der Weihinschrift der Mikythe am Schaft der Pfeilerbasis Kat. 2.12 ist in dieser Hinsicht bemerkenswert, findet im ausgehenden 6. bzw. im Laufe des 5. Jh. v. Chr. aber weitere Parallelen, z. B. DAA $278=$ IG I³ 632 (510-500 v. Chr.?); DAA 287 = IG I³ 890 (um 440 v. Chr.?). 373 Zur Nachzeitigkeit des Geschriebenen siehe unten Kapitel III, S.180-187. 
Das Spektrum der Statuen, die auf den hier besprochenen Basen standen, war, auch wenn diese ausnahmslos verloren sind und allenfalls anhand der Einlassungsspuren rekonstruiert werden können, mit Darstellungen von Göttern und menschlichen Individuen weit gefasst, ohne dass sich damit ein enger gefasster semantischer Zusammenhang zwischen der Oberflächengestaltung und einem spezifischen Bildthema erkennen ließe. Einmal mehr zeigt dieser Umstand, dass die dekorative Unfertigkeit in erster Linie zur repräsentativen bzw. ästhetischen Aufwertung des Unterbaus des statuarischen Monuments und damit des gesamten Ensembles diente.

\section{Avant la lettre: Die Basis der Phrasikleia und die Ursprünge der dekorativen Unfertigkeit}

Die zuvor besprochenen ,unfertigen' Statuenbasen entstanden, wie bereits eingangs konstatiert wurde, weitgehend in der ersten Hälfte des 5. Jhs. v. Chr., sieht man von einigen wenigen jüngeren Exemplaren ab. Diese chronologische Geschlossenheit täuscht aber insofern, als sich mit einiger Wahrscheinlichkeit ein älterer Vorläufer der nun hinlänglich bekannten Gestaltungsweise benennen lässt, der trotz seiner forschungsgeschichtlichen Prominenz in dieser Hinsicht bislang unerkannt geblieben ist: Es handelt sich um die im dritten Viertel des 6. Jh. v. Chr. entstandene Statuenbasis der Phrasikleia-Kore aus dem attischen Merenda. ${ }^{374}$ Bei dem Deckblock einer Stufenbasis werden die vier geglätteten Stirnseiten an ihren vertikalen Außenkanten sowie an der oberen horizontalen Blockkante von dünnen Ritzlinien gerahmt (Abb.2.13a.b). Dementsprechend setzen sich aus einer Doppellinie und einer einfachen Linie drei $\Pi$-förmige Streifen zusammen. ${ }^{375}$ Zumindest der breitere Mittelstreifen war dabei ursprünglich mit einer roten Farbe gefasst, von der sich auf der Frontseite sowie auf der linken Nebenseite wenige Reste erhalten haben. ${ }^{376}$ In den

374 Athen, Nationalmuseum Inv. 4889; vgl. Kissas 2000, 47 Nr. A 14; Barlou 2014, 180f. Nr. 53 (mit Lit.); siehe auch Brinkmann 2010.

375 Abbildungen aller Basisseiten finden sich bei Butz 2010, 82f. Abb.46-49. Die Ritzlinien an der Oberkante haben sich lediglich auf den Nebenseiten erhalten. Die Vorder- und Rückseite wurden bereits in der Antike stark abgemeißelt, um die Statue möglichst unbeschädigt aus der Basis zu entfernen. Auf der rechten Nebenseite findet sich am rechten Blockrand anstelle einer einfachen Linie eine zweite Doppellinie. Möglicherweise handelt es sich um einen Fehler bei der Ausführung durch den Steinmetz. Vgl. Keesling 1999, 520; siehe auch oben Kapitel I, S.74-76. DNO I 348 geht fälschlicherweise von lediglich „zwei parallelen Ritzlinien“ aus.

376 Keesling 1999, 520; siehe die Farbabbildung der linken Nebenseite der Basis bei Brinkmann/ Koch-Brinkmann/Piening 2010, 188 Abb.133. Bedauerlicherweise wurde die Basis nicht in die Untersuchung von V. Brinkmann ebd. zur Polychromie der Phrasikleia-Kore miteinbezogen, siehe die Farbrekonstruktion bei Brinkmann/Koch-Brinkmann/Piening 2010, 204 Abb.156. Hier sind ausschließlich die beiden Inschriften mit roter Farbe angegeben worden. Zur Funktion von Ritzlinien in der archaischen Plastik als Begrenzung des Farbauftrages: Keesling 1999, 519. 

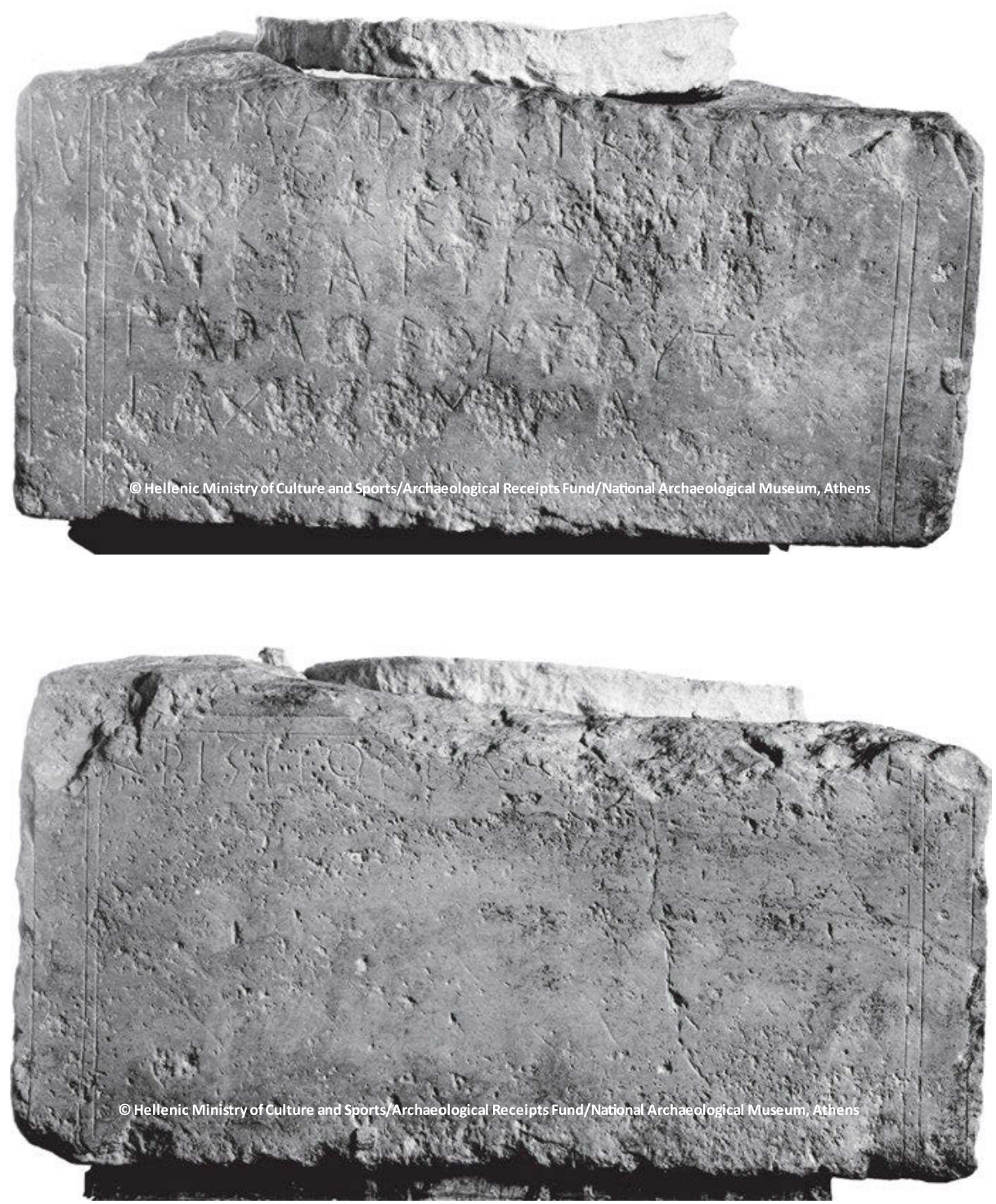

Abb. 2.13a-b: Front- und rechte Nebenseite der Basis der Phrasikleia, drittes Viertel 6. Jh. v. Chr. (Athen, National Museum 4889). 
so eingefassten Mittelfeldern dieser beiden Seiten standen das Grabepigramm für Phrasikleia bzw. die Künstlersignatur des ausführenden Bildhauers Aristion von Paros. ${ }^{377}$
A: $\quad \sigma \tilde{\varepsilon} \mu \alpha \Phi \rho \alpha \sigma ı \kappa \lambda \varepsilon i ́ \alpha \varsigma^{*}$

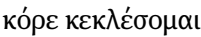
aikí, ảvtì yáno

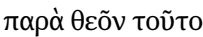

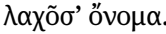

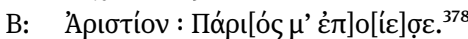

Neben seiner literarischen Qualität zeichnet sich das Grabepigramm insbesondere unter dem Gesichtspunkt des Layouts aus: Es handelt sich um ein frühes, wenn nicht sogar das früheste attische Zeugnis einer stoichedon-Inschrift, einer Gestaltungsweise, die sich erstmals im inselionischen Raum und insbesondere auf Samos vor der Mitte des 6 Jhs. v. Chr. beobachten lässt. ${ }^{379}$ Dass man die Inschrift hingegen im altattischen Alphabet verfasste, ist sicherlich zum einen auf die Identität der Auftraggeber zurückzuführen. ${ }^{380}$ Der Befund wird zum anderen aber auch durch den Umstand erhellt, dass für die Inschriften aus dem Euvre des Aristion drei ausführende Hände unterschieden werden können: Offensichtlich war es also nicht Aristion selbst, der die Inschrift anbrachte, sondern zu diesem Zweck angeheuerte Steinmetze, die daneben auch für die Bildhauerwerkstatt des Phaidimos, eines Zeitgenossen des Aristion, tätig waren. ${ }^{381}$ In der Ausführung des stoichedon zeigt sich freilich nicht die Konsequenz, wie sie eingangs an der Antenor-Basis beobachtet wurde, vielmehr fallen Zeilen- und Wortenden zusammen. Das führt zu einem unregelmäßigen ,Ausfransen der Inschrift an ihrem rechten Ende, während sich die Zeilenanfänge in einem nahezu einheitlichen Abstand an dem Randstreifen orientieren. Die auf den ersten Blick durchaus ansprechende Vermutung, dass die Randstreifen dementsprechend als Rahmung des Geschriebenen dienten, greift indes zu kurz. ${ }^{382}$ So lässt nämlich gerade die allseitige, mithin von den Inschriften zunächst einmal unabhängige Ausführung keinen anderen Schluss zu, als dass es sich primär um ein Schmuckelement der Basis selbst handelt. ${ }^{383}$

377 IG I 1261 = DNO I 348. Zu Aristion von Paros: Walter-Karydi 2001a, 83-85; Barlou 2013; DNO I 347-350.

378 A: „Grabmal der Phrasikleia. Jungfrau werde ich immer heißen: statt der Hochzeit habe ich von den Göttern diesen Namen erlost.“ B: „Aristion aus Paros hat mich gefertigt.“(Übers. Klaus Hallof). 379 Butz 2010, 79-103 zur Herkunft und Genese des stoichedon.

380 Zur Rolle des Auftraggebers bei der Wahl von Schrift und Dialekt in Inschriften siehe hier Anm. 334. 381 Jeffery 1962, 151f.; Barlou 2013, 115. Vgl. Hochscheid 2015, 237; Hurwit 2015, 141f. Zu Phaidimos: Vollkommer 2004, 208f.; DNO I 358-360.

382 So etwa Keesling 1999, 520: „the epitaph inscribed on the front face of the base was framed by two parallel borders“.

383 So mit Recht auch C. Reinhardt oben in Kapitel I, S.75f. 
Die sich unweigerlich aufdrängende Frage, was es mit diesem spezifischen Dekor auf sich hat, ist von der archäologischen Forschung bislang weitgehend unbeantwortet geblieben, bzw. sie wurde, weil der Fokus vornehmlich auf dem Bildwerk selbst lag, überhaupt nicht gestellt. Neben forschungsgeschichtlichen Bedingtheiten mag das auch dem zumindest vordergründigen Mangel an stichhaltigen Parallelen geschuldet sein, zumal die zwei anderen Basen, die Aristion auf Grundlage des epigraphischen Befundes mehr oder weniger sicher zugewiesen werden, eben keine vergleichbare Gestaltungsweise zeigen. ${ }^{384}$ Verschiedentlich hat man in der Forschung deshalb auf die um 530-520 v. Chr. entstandene Neilonides-Basis verwiesen, auf deren Frontseite sich eine geritzte und mit roter Farbe gefasste rechteckige Rahmung nachweisen lässt. Im Gegensatz zur Phrasikleia-Basis wurde sie aber allenfalls auf der geglätteten linken Nebenseite wiederholt, wo die ältere Forschung noch Reste einer möglichen weiteren Rahmung sah. ${ }^{385}$ Catherine Keesling vermutete deshalb, dass diese Seite ursprünglich für die Anbringung der Künstlersignatur vorgesehen gewesen sein könnte, ehe man jene zusammen mit der Grabinschrift schließlich auf die Front gesetzt hat. ${ }^{386}$ Dies dahingestellt, wird in jedem Fall deutlich, dass sich bei der Rahmung anders als bei der Phrasikleia-Basis eben nicht um einen Dekor des Blockes an sich handelt, sondern - und das ist als Beobachtung en passant höchst bemerkenswert - offenbar im Wechselspiel mit weiteren Gestaltungselementen wie möglicherweise den Inschriften stand. Als Vergleich dient außerdem eine fragmentarisch erhaltene archaische Grabstele von der Athener Agora, deren seitliche Blockkanten von einer doppelten Ritzlinie eingefasst werden. ${ }^{387}$ Vergleichbare Rahmungen mit Leisten oder auch mit Ornamentbändern, wenngleich in aller Regel plastisch gearbeitet, sind freilich durchaus charakteristisch für diese Gattung in der Archaik, sofern sie figürliche Darstellung tragen. ${ }^{388}$ Gleiches gilt denn auch für zeitgenössische Statuenbasen: An ihnen finden sich plastische Leisten m. W. ausschließlich in Kombination mit figürlichem Bildschmuck, was im Übrigen, wie zuvor schon angedeutet, eine weitere raison d'être der Rahmung an der Neilonides-Basis darstellen dürfte. ${ }^{389}$

384 IG I3 1208; vgl. Kissas 2000, 51f. Nr. A 18 mit Abb. 23; DNO I 347, IG I3 1211; vgl. Kissas 2000, 51-54 Nr. A 19 mit Abb. 27; DNO I 349. Es handelt sich wie bei der Phrasikleia-Basis auch in diesen Fällen um Deckblöcke von Stufenbasen. Vgl. Barlou 2013, 111f.

385 Zur Neilonides-Basis: Keesling 1999, bes. 519f. (Rahmung). 526 Anm. 78 (Spuren einer potentiellen Rahmung auf der linken Nebenseite, die im Vergleich mit der rechten Nebenseite deutlich stärker geglättet ist). Einen Vergleich mit der Basis der Phrasikleia ziehen Keesling 1999, 520 Anm. 48, wie auch C. Reinhardt oben in Kapitel I, S. 75. Dazu: Kissas 2000, 62f. Nr. A 29; DNO I 378.

386 Keesling 1999, 526 Anm. 78.

387 Keesling 1999, 520 Anm. 48. Zur besagten Stele von der Athener Agora: Richter 1961, 44 Nr.60B mit Abb.150.

388 Exemplarisch nur Richter 1961, 20f. Nr.23 mit Abb.86, 22 Nr. 27 mit Abb. 83, 27-29 Nr. 37 mit Abb. 99, 32f. Nr. 45 mit Abb.126, 44 Nr. 61 mit Abb.147, 47 Nr. 67 mit Abb.156. Siehe dazu auch oben Kapitel I, S. 73-80.

$389 \mathrm{Zu}$ archaischen Basen mit figürlichen Darstellungen und ihren Rahmungen: Kosmopoulou 2002, $17,36-63$. 
Zurück zur Basis der Phrasikleia und ihrem Dekor: Blickt man zurück auf die zuvor vorgestellten, unter den Vorzeichen von Unfertigkeit gearbeiteten Statuenbasen liegt es m.E. nahe, die П-förmige Rahmung als graphische Wiedergabe eines üblicherweise von einem Steinmetz durchgeführten Fertigungsprozesses zu deuten. Sie differenziert die Oberfläche der glatten Stirnseiten in Randschlag und Spiegel. Mit der Basis der Phrasikleia wäre damit ein früher Vorläufer dieser spezifischen Gestaltungsweise gewonnen, die sich aber, soweit fassbar, in der zeitgenössischen Praxis nicht weiter etablierte. ${ }^{390}$ Wie auch bei der jüngeren Alkibios-Basis (Kat. 2.1) bereits beobachtet, bleiben Oberflächengestaltung und Inschrift additive Gestaltungselemente, die in keiner engeren Beziehung zueinander standen.

Weiter erhärtet wird die hier vorgeschlagene Deutung der Phrasikleia-Basis durch die ,künstlerische Sozialisation“ des Aristion. Wenn nämlich bereits Nikolaos Kontoleon den Dekor mit einem vagen Verweis auf samische Palmettenstelen als „un élément ionien, dû probablement à l'origine d'Aristion“, auffassen wollte, dann vermag der Vergleich an sich zwar nicht zu überzeugen, trifft im Wesentlichen aber eben doch das Richtige. ${ }^{391}$ Dass sich im Euvre des Aristion spezifische Charakteristika der parischen Kunstlandschaft widerspiegeln, wurde in der Forschung lange Zeit in Frage gestellt, nicht zuletzt weil man gerade im Falle der Phrasikleia eine Nähe zu verschiedenen attischen Werken wie z. B. der ,Berliner Göttin` auszumachen glaubte. ${ }^{392}$ Bestechend hat aber zuletzt Vasiliki Barlou unter der von attischen Motiven geprägten Ikonographie der Phrasikleia dezidierte stilistische Züge einer parischen Bildhauertradition offengelegt. ${ }^{393}$

Diese Beobachtungen werfen denn auch ein bezeichnendes Schlaglicht auf die Oberflächengestaltung der Phrasikleia-Basis: Zwischenstadien bei der Zurichtung von Werksteinblöcken wurden nämlich im ionisch-kykladischen Raum bereits seit dem 6. Jh. v. Chr. als ornamentale Schmuckform verwendet, wobei sich dieses Phänomen vornehmlich in der Architektur beobachten lässt. ${ }^{394}$ Verwiesen sei in diesem

390 Allein die im letzten Viertel des 6. Jhs. v. Chr. entstandene Basis des Leanax könnte als freilich durchaus problematisches Vergleichsbeispiel in Betracht gezogen werden, siehe dazu: $I G \mathrm{I}^{3} 1365=$ DNO I 378; vgl. Kissas 2000, 61f. Nr. A 28. Nach Viviers 1992, 107 zeigt die Frontseite der Basis nämlich „un listel d'env. 0,003, travaillé au ciseau et poli, le long des arêtes supérieure et verticales“. Diese eventuelle Rahmung blieb aber bei der Anbringung der Inschrift unberücksichtigt, wie es denn auch keine Hinweise auf ihre farbige Fassung gibt. Ihr einstiger Zweck bleibt damit unklar.

391 Kontoleon 1970, 91f. (Zitat auf S. 92); gefolgt von Barlou 2014, 181.

392 Eine Synopse der Forschungsdiskussion findet sich bei Barlou 2013, 112-115; Barlou 2014, 84 mit Anm. 664.

393 Barlou 2013; Barlou 2014, 84-86. Vgl. bereits Kaltsas 2002, bes. 18f. Einen kykladischen Einfluss sah Barlou 2013, 111f. darüber hinaus auch im Falle einer bzw. nach Barlou zweier Grabsäulen, die ebenfalls von Aristion von Paros geschaffen wurden, siehe dazu IG I³ 1269 = DNO I 350; vgl. Kissas 2000, 79 Nr. A 47. Im Gegensatz zur landläufigen Verwendung dieses Typus als Votivträger in attischen Heiligtümern sei er in Grabkontexten nur in geringer Zahl bezeugt und habe erst durch den Einfluss von kykladischen Bildhauern Verbreitung gefunden. Archaische Grabsäulen sind allerdings auch im ionischen Raum nur in geringer Zahl bezeugt, siehe dazu McGowan 1995, 615 Anm. 2.

394 Lauter 1983, 297-301; Kalpaxis 1986, 42, 82f., 122-124; Altekamp 1991, 376; Dirschedl 2017, 65. 


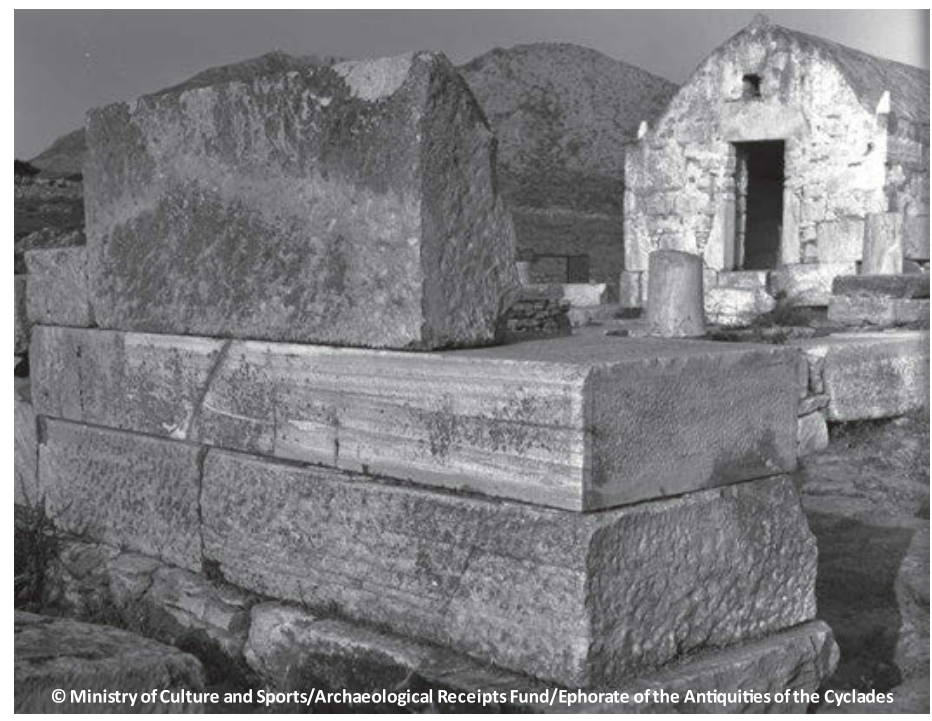

Abb. 2.14: Anathyroseartiger Mauersockel am Tempel von Sangri (Naxos), drittes Viertel 6. Jh. v. Chr.

Zusammenhang nur auf die aufwendig angelegten Spiegelbossen am Sockel des wohl im dritten Viertel des 6. Jhs. v. Chr. entstandenen Altars vom Kap Monodendri, ${ }^{395}$ die anathyroseartigen Spiegelquader am zeitgenössischen Demeter-Tempel bei Sangri auf Naxos (Abb. 2.14) ) $^{396}$ oder etwa auf die mit feinem Randschlag gearbeiteten Krepisblöcke am Schatzhaus von Massalia in Delphi, das im letzten Viertel des 6. Jh. v. Chr. womöglich von einer Bauhütte aus Phokaia errichtet wurde. ${ }^{397}$ Über den frühen Sonderfall der Phrasikleia-Basis hinaus bietet dieses besondere Charakteristikum der ionisch-kykladischen Steinmetztradition eine naheliegende Erklärung für das Aufkommen des Phänomens der dekorativen Unfertigkeit im spätarchaischen Athen.

\section{Neue visuelle Ästhetik: Ionische Bildhauer im spätarchaischen Athen}

Seit dem mittleren 6. Jh. v. Chr. lässt sich eine ausgeprägte Präsenz ionischer bzw. kykladischer Bildhauer in Athen anhand von Künstlersignaturen nachweisen. Dieser Umstand ist zum einen auf die kulturelle Sogkraft der Polis zurückzuführen, die, wie zuvor schon erwähnt, mit der offiziellen Repräsentation der Peisistratiden und einer entsprechenden Inszenierung Athens als,ältester Stadt Ioniens‘ im Einklang

395 Zuletzt Mert 2017, bes. 193-195 zur Datierung (mit Lit.); vgl. Kalpaxis 1986, 24 mit Taf. I, 2.

396 Lauter 1983, 299f. mit Abb. 8; Gruben 1997, 263 Abb. 1, 266f. mit Anm. 8 (mit Lit.). Vgl. Ohnesorg 2005, 106-109 mit Abb. 50 für die ähnliche Sockelgestaltung eines wohl noch spätarchaischen Altars im Poseidon-Heiligtum von Thasos.

397 Daux 1923, 52 Abb. 54 und Taf. XVI. Allgemein zum Schatzhaus: Partida 2000, 230-247, bes. 234 mit Anm. 19 zur möglichen Ausführung durch eine phokäische Bauhütte; Hering 2015, 112-115 (mit Lit.). 
stand. ${ }^{398}$ Wesentliche Faktoren dürften zum anderen aber auch der gegen Ende des 6. Jhs. v. Chr. stetig wachsende politische wie ökonomische Druck des Perserreiches auf die griechischen Poleis an der Westküste Kleinasiens, die daraus resultierenden innerstädtischen staseis und schließlich der im Jahre 500/499 v. Chr. ausbrechende Ionische Aufstand gewesen sein. ${ }^{399}$ In vielfacher Hinsicht wurde die materielle Kultur Athens dieser Zeit, sei es in der Vasenmalerei, der Architektur oder der Skulptur, beispielsweise mit der Einführung des Schrägmantels in die Ikonographie der Korenstatuen oder der zunehmend verbreiteten Darstellungen des Sitzmotivs im Grabkontext, von einer neuen ,ionisierenden' Ästhetik geprägt. ${ }^{400}$

Künstler wie Aristion von Paros ${ }^{401}$ oder Pythis ${ }^{402}$, Endoios und Philergos ${ }^{403}$, die entgegen der späteren literarischen Überlieferung aus Ionien stammen dürften, sowie die chiotische Bildhauerfamilie des Archermos, Boupalos und Athenis ${ }^{404}$ arbeiteten dabei nicht nur für athenische Auftraggeber, sondern vielfach auch für in Athen ansässige Ionier, die offenbar gezielt nach den ihnen vertrauten Formen verlangten. ${ }^{405}$ Die von Philergos geschaffene Sitzstatue des Samiers Leanax oder das statuarische Monument gleichen Typus für den Naxier Anaxilas aus dem Kerameikos, die beide ausschließlich in Form ihrer Basen erhalten sind, legen davon exemplarisch Zeugnis $\mathrm{ab.}^{406}$

Vor dem Hintergrund dieser Gemengelage, die von der Bewahrung des Eigenen im Fremden bzw. von einer in eine ästhetische Mode verkehrten Exotik des Fremden bestimmt wurde, muss auch das Phänomen der dekorativen Unfertigkeit verstanden werden: Von Künstlern wie Aristion von Paros oder dem namentlich unbekannten chiotischen Bildhauer der Basis Kat. 2.2 in Athen bekannt gemacht, wurde diese neue Art der Oberflächengestaltung sukzessiv in das Formenrepertoire lokaler

398 Shapiro 1989, 48f., 103f.; Welwei 2011 (Teil I), 244. Zur ,Kulturpolitik‘ der Peisistratiden im Bereich der Musik und Dichtung siehe hier auch Anm. 333.

399 Vgl. D’Onofrio 1998, 113-116; Welwei 2011 (Teil II), 27-31.

400 Zur Vasenmalerei: Jackson 1976, bes. 80-86. Zur Verbreitung von Votivsäulen: Donos 2008, 4148; Kissas 2000, 21-28. Zur Skulptur: Pedley 1978; Viviers 1992, bes. 206-218; Tölle-Kastenbein 1992, bes. 137f.; Franssen 2011, 144 mit Anm.36; Barlou 2013. Zum Motiv des Sitzens siehe auch Keesling 1999, 532-536.

$401 \mathrm{Zu}$ Aristion von Paros siehe hier Anm. 377.

402 Wagner 2004, 338; DNO I 413-414.

403 Für eine ionische Herkunft des Endoios und Philergos: Viviers 1992; Keesling 1999, 523-528; Andreiomenou 2006, bes. 52. Dagegen konstatiert u. a. Paus. 1, 26, 4 die athenische Abstammung des Endoios. Dementsprechend auch Brinkmann 2001, 204f.; DNO I 361-370.

$404 \mathrm{Zu}$ Archermos, Boupalos und Athenis siehe hier Anm. 339.

405 In diesem Zusammenhang Viviers 1992, 217: „On ne peut donc nier qu'il s’agit là, du moins à l'origine, d'une réponse spécifique à la demande d'une clientèle bien définie.“ Vgl. Kaczko 2010, 211; Hochscheid 2015, 271f.

406 Zur Basis des Leanax siehe hier Anm. 390. Zur Basis des Anaxilas: IG I 1357 (um 510-500 v. Chr.); vgl. Kissas 2000, 62f. Nr. A 29. 
Bildhauerwerkstätten wie z. B. des Kritios und Nesiotes übernommen. Dagegen hielt man, wie gezeigt wurde, für die Praxis des Beschreibens weitgehend an Vertrautem fest. Allein, dass ein derartiger Rezeptionsprozess nicht ohne Weiteres unterstellt werden kann, zeigt der Umstand, dass sich vergleichsweise im naheliegenden Bereich der öffentlichen Bautätigkeit Athens der motivische Gebrauch von dekorativer Unfertigkeit erst vermehrt um die Mitte des 5. Jhs. v. Chr. nachweisen lässt. ${ }^{407}$ Umso prägnanter ist deshalb die Rolle der Statuenbasen als Vorläufer dieser Entwicklung.

\section{Zerstörte Tempel: Dekorative Unfertigkeit im Zeichen der Perserkriege?}

Gegenüber einer dezidiert dekorativen Qualität von Werkzoll, Bossierung oder Randschlag und Spiegel ist der ,Erfolg“ dieser Oberflächengestaltung an den Statuenbasen des frühen 5. Jhs. v. Chr. nach Catherine Keesling auf einen anderen Grund zurückzuführen, nämlich auf ihre Semantisierung als lieu de mémoire im erinnerungskulturellen Diskurs der Perserkriege: Ihre spezifische Bearbeitungsweise erinnere nämlich an die unfertigen Bauglieder des von den Persern im Jahre 480 v. Chr. zerstörten Vorparthenon. ${ }^{408}$ Es vermag wohl nicht zu verwundern, dass dieses Sakrileg in der Tat die zeitgenössischen Diskurse bestimmte, auch wenn es sich bei dem sog. Eid von Plataiai mit seiner Bestimmung, die von den Persern zerstörten griechischen Heiligtümer nicht wieder aufzubauen, um eine retrospektive Fiktion des 4. Jhs. v. Chr. handeln dürfte. ${ }^{409}$ So lässt etwa Aischylos in seiner im Jahre 472 v. Chr., mithin nur acht Jahre

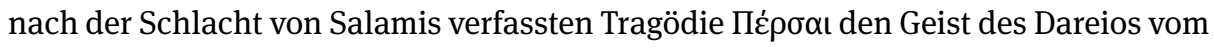
Frevel des persischen Heeres berichten:

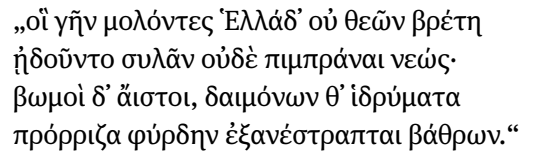

„Die sich auf Hellas’ Boden Götterbilder nicht gescheut zu rauben noch Brand zu legen an ihr Haus: Altäre - spurlos fort, der Gottheit Bilder - ganz entwurzelt, um und um gestürzt aus Sockels Grund.“410

Und mehr noch, im Zuge der Aufräumarbeiten auf der Akropolis, die man bereits in den frühen 470er Jahren begonnen hatte, wurden die unfertigen Säulentrommeln des Vorparthenon sowie Partien des Gebälks des ebenfalls zerstörten Alten Athenatempels

407 Kalpaxis 1986, 125. Zur Athener-Halle in Delphi siehe hier Anm. 414.

408 Keesling 2010, 125-128, bes. 127.

409 Siehe dazu Miles 2014, bes. 129-133 (mit Lit.).

410 Aischyl. Pers. 809-812. 
weithin sichtbar in der neu errichteten Nordmauer verbaut. Der Denkmalcharakter dieser Wiederverwendung ist schwerlich zu leugnen. ${ }^{411}$

Entscheidend für die von Keesling vertretene Hypothese ist der Umstand, dass eine Unfertigkeit suggerierende Oberfächengestaltung an mehreren, im historischen Umfeld der Perserkriege entstandenen Denkmälern nachgewiesen werden kann. ${ }^{412}$ Lässt man das Anathem des Kallimachos (Kat. 2.17) mit seinem Werkzoll tragenden Säulenschaft aufgrund der älteren Datierung außer Acht, ${ }^{413}$ betrifft das a) die vielleicht nach der Schlacht von Sestos 479/478 v. Chr. entstandene Stoa der Athener im Heiligtum von Delphi, deren anathyroseartig bearbeitete Krepis die Weihinschrift trägt, ${ }^{414} \mathrm{~b}$ ) zwei mit Randschlag und Spiegel verzierte Basen eines auf der Akropolis geweihten Beuteanathems aus den Jahren nach 480 v. Chr., ${ }^{415}$ c) ein am Schauplatz der Schlacht von Marathon um 470-460 v. Chr. aufgestelltes Tropaion in Form einer unkannelierten, in Werkzoll belassenen Säulenbasis der ionischen Ordnung ${ }^{416}$ sowie d) mehrere anathyroseartig bearbeitete Blöcke, die, beschriftet mit Epigrammen für im Kampf gefallene Athener, einem wohl aus dem demosion sema stammenden Kenotaph zugewiesen werden können. Seine Verbindung mit der Schlacht von Marathon bzw. Salamis und dementsprechend auch die ins frühe 5. Jh. v. Chr. fallende Datierung werden in der Forschung kontrovers diskutiert. ${ }^{417}$ Für diese räumlich getrennten und typologisch völlig unterschiedlichen Einzelmonumente wurde dem antiken Betrachter nach Keesling durch die einheitliche Oberflächengestaltung ein „visual link“ geboten, der sie als kohärente Denkmalgruppe zu erkennen gab und darüber hinaus auch, wie bereits erwähnt, den Bezug zur unfertigen Architektur des Vorparthenon

411 Kousser 2009, bes. 270-272; Miles 2014, $123 \mathrm{f}$.

412 Unter die unten angeführten Denkmälern wollte C. Keesling auch die auf der Agora aufgestellte Statuengruppe der Tyrannenmörder einreihen. Für das im Bereich der Agora gefundene Basenfragment, das wohl mit der von Kritios und Nesiotes geschaffenen Neuaufstellung des von den Persern verschleppten Originals zu verbinden ist, konstatierte Keesling 2010, 127 dementsprechend: „the presence of a stippled surface just below the inscription is faintly detectable. “Vgl. Keesling 2017, 26. Dem Verf. war es nicht möglich eine derartige Bearbeitung zu verifizieren. Vielmehr scheint die Oberfläche der Basisstirn auch im Bereich der Buchstaben flächig leicht gezahnt worden zu sein, was, wie bereits erwähnt, durchaus übliche Praxis war, siehe hier Anm. 308. Zum Basisfragment: IG I 502; vgl. Brunnsåker 1971, 84-98 mit Taf. 22; Kissas 2000, 284 Nr. C 83; Krumeich 2007, 10-12; DNO I 561. Für eine qualitätsvolle Abbildung siehe Ober/Hedrick 1993, 55 Abb. 4.1.

413 Nicht zu überzeugen vermag in diesem Zusammenhang die Beschreibung von Keesling 2010, 126, dass die Säulenbasis „imitated the appearance of earlier private dedications, among which the architectural style originated as a surface treatment with no special significance. “ [Hervorhebung durch den Verf.]. Es handelt sich hierbei aber eben nicht um eine Form der Rezeption, sondern vielmehr um den Ausdruck ein und desselben ästhetischen Phänomens.

414 Amandry 1953, bes. 37-39 mit Taf. 21-23. Zur Weihinschrift: IG I³ 1464. Vgl. Gauer 1968, $101 \mathrm{f}$.

$415 \mathrm{Zu}$ diesem Weihgeschenk siehe hier Anm.343.

416 Vanderpool 1966; Rabe 2008, 101-104 (mit Lit.); jetzt Korres 2017.

417 IG I3 503/504; vgl. Matthaiou 1988; Jung 2006, 84-96 (mit ausführlicher Darstellung der kontroversen Forschungspositionen); Arrington 2015, 43-46 (mit Lit.). 


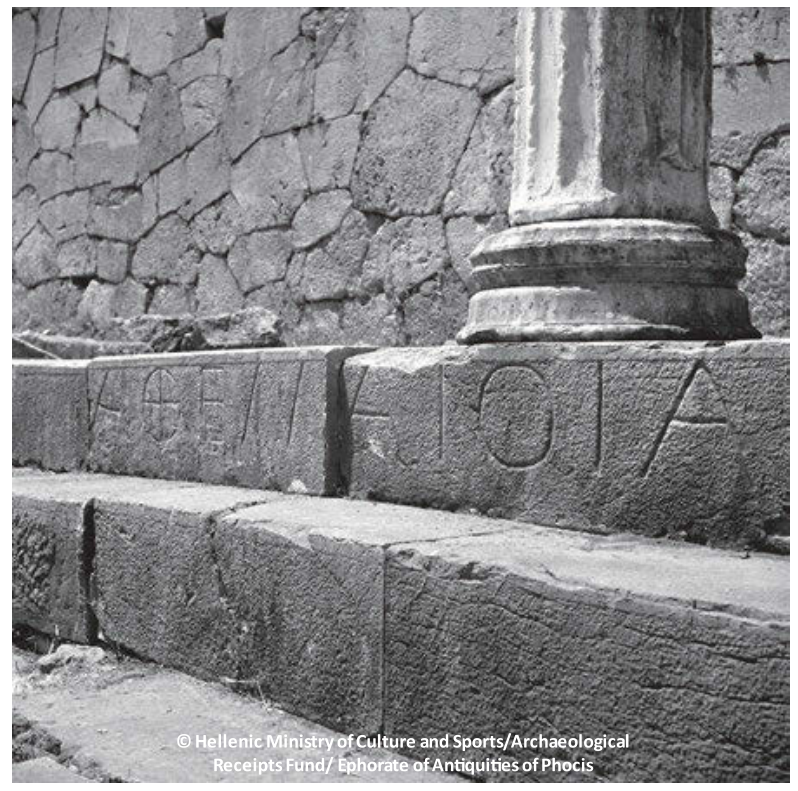

Abb. 2.15: Krepis und Säulenbasis der sog. Athener-Halle in Delphi, nach $479 / 478$ v. Chr.

vermittelte. Die Signifikanz dieser Monumente im kollektiven Gedächtnis Athens habe wiederum zur Popularität des „architectural style“ im Rahmen der privaten Votivpraxis beigetragen. ${ }^{418}$

Ohne dass es an dieser Stelle möglich oder auch notwendig ist, alle genannten Denkmäler im Einzelnen zu besprechen, erscheint die Athener-Halle in Delphi besonders geeignet, um diese Hypothese zu überprüfen. In prominenter Position wurde die Stoa am oberen Ende der heiligen Straße gegen die polygonale Stützmauer der Tempelterrasse errichtet. ${ }^{419}$ Die Stirnseiten ihrer noch in situ liegenden Krepis wurden, wie bereits erwähnt, anathyroseartig zugerichtet, wobei die Stylobatstufe die eigentliche Weihinschrift trägt (Abb. 2.15).

Ohne eine Glättung sind hier die Buchstaben, die sich mit einer außergewöhnlichen Höhe von ca. $18 \mathrm{~cm}$ nach archaischer Praxis dicht an die Unterkante des Randschlages drängen, direkt in den gespitzten Spiegel, in Einzelfällen sogar über Fugen hinweg eingemeißelt worden. ${ }^{420}$ Auffälliger als diese Bearbeitung sind indes die Säulenbasen, die der Stoa auf sicherer Grundlage zugewiesen werden können und in der Forschung lange Zeit als singulär in ihrer Form betrachtet wurden. ${ }^{421}$ Tatsächlich handelt es sich um einen äußerst ungewöhnlichen Rückgriff auf einen Basentypus, der in Kleinasien um die Mitte des 6. Jhs. v. Chr. bis in das dritte Viertel dieses

418 Keesling 2010, $127 \mathrm{f}$.

419 Zur Lage und Architektur der Stoa siehe Amandry 1953.

420 Siehe hier Anm. 414.

421 Amandry 1953, 40-44, 95-98 mit Taf. XXIV, wonach eine der Basen noch in situ aufgefunden wurde. 


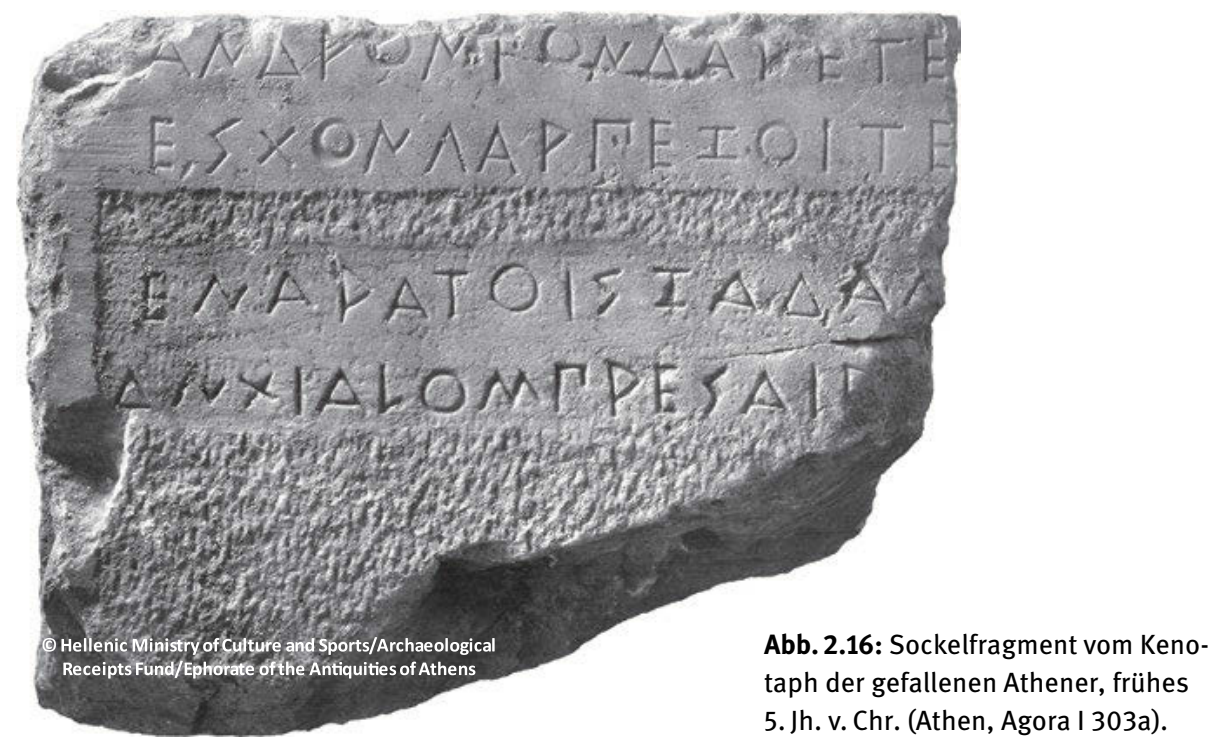

Jahrhunderts an einigen wenigen Bauwerken wie dem älteren Artemision von Ephesos oder dem älteren Apollon-Tempel in Didyma verbreitet war. ${ }^{422}$

Ob diese überraschende Wahl, wie Burkhardt Wesenberg vermutete, tatsächlich einen Hinweis auf den Schauplatz des Krieges bieten sollte, dessen Beute gemäß der Weihinschrift in der Stoa ausgestellt war, sei dahingestellt. ${ }^{423}$ Wesentlich erscheint vielmehr, dass die Halle offensichtlich absichtsvoll in eine dezidiert altertümlich,ionisierende` Atmosphäre gekleidet wurde, die sich Betrachter natürlich vorderhand durch vertraute Elemente der Bauornamentik wie den ionischen Kapitellen, zugleich aber auch anhand von Details wie den kannelierten Tori der ansonsten wohl eher fremd wirkenden Basenform erschloss. ${ }^{424}$ In diesem Zusammenhang muss sicherlich auch die ,unfertige“ Bearbeitung der Krepis verstanden werden: Sie diente als komplementäres, ,ionisierendes` Dekorelement und eben nicht als Sinnbild der Perserzerstörung auf der Akropolis.

Damit stößt man zugleich zum Problem von Keeslings Argumentation vor, welche die Kontinuität einer spätarchaischen Ästhetik der dekorativen Unfertigkeit, wie sie hier dargelegt wurde, ohne Weiteres negiert bzw. der Deutungshoheit der Perserkriege unterordnet. Eine Gegenprobe erlaubt die vielleicht kurz nach 480 v. Chr. entstandene Quaderbasis des Metöken Hegelochos aus der Bildhauerwerkstatt des Kritios und Nesiotes, bei dem es sich nach Name und Dialekt um einen Ionier handeln

422 Wesenberg 1971, 130-141; so auch jüngst Dirschedl 2013, 275-284. Es stellt sich die Frage, inwieweit die Rezeption dieser seltenen Basenform an der Athener-Halle auf die Beteiligung einer ionischen Bauhütte oder eines ionischen Architekten schließen lässt.

423 Wesenberg 1971, 141. Vgl. Amandry 1953, 115 Anm.1.

$424 \mathrm{Zu}$ den erhaltenen ionischen Kapitellen der Stoa: Amandry 1953, 45-47, 98-101. 
dürfte. ${ }^{425}$ Die Einlassungsspuren auf der Oberseite der Basis geben zu erkennen, dass das Weihgeschenk als leicht überlebensgroße Bronzestatue im weiten Ausfallschritt $\mathrm{zu}$ rekonstruieren ist, die mit einiger Sicherheit den Stifter als gerüsteten Krieger zeigte. ${ }^{426}$ Diesem Thema entspricht auch die in stoichedon verfasste Weihinschrift an Athena, welche das Anathem als mnema der von Hegelochos im Krieg, und zwar mit hoher Sicherheit im Kampf gegen die Perser, auf sich genommenen Anstrengungen zu erkennen gibt. ${ }^{427}$ Anzeichen einer ,Unfertigkeit‘ suggerierenden Oberflächengestaltung, durch die das Weihgeschenk, folgt man Keeslings Hypothese, in den Kreis der öffentlichen Denkmäler treten und damit zusätzlich aufgewertet werden würde, sucht man freilich vergebens. Andererseits stellt sich im Falle von Stiftern wie Mikythe (Kat. 2.12) oder Pyres (Kat. 2.22) die Frage, ob ihren Weihgeschenken nicht ähnliche Mechanismen der Identitätsvergewisserung zugrunde liegen, wie sie zuvor für die älteren statuarischen Monumente des Leanax oder Anaxilas konstatiert wurden.

Kehren wir abschließend im Zusammenhang mit den Persermonumenten noch einmal auf die Praxis des Beschreibens zurück, der gerade an dem zuvor erwähnten Gefallenenkenotaph aus dem demosion sema eine besondere Bedeutung zufällt (Abb. 2.16). ${ }^{428}$ Die fragmentarisch erhaltenen, anathyroseartig bearbeiteten Blöcke sind in Form eines längeren Sockels zu ergänzen und trugen mehrere, heute nicht mehr erhaltene Stelen, auf denen man sich in Analogie zu anderen Monumenten wohl Gefallenenlisten vorzustellen hat. ${ }^{429}$ In inzwischen bekannter Weise wurden die zweizeilig in stoichedon angelegten Epigramme in den horizontal an der oberen Blockkante verlaufenden Randschlag gesetzt, der aus diesem Grund deutlich breiter ist. In einer späteren Phase hat man den gespitzten Spiegel auf identischer Breite für die Anbringung eines zweiten Epigramms geglättet. Fern jeder visuellen Bezugnahme auf die Perserzerstörung ${ }^{430}$ scheint diese Art der Oberflächenbearbeitung vornehmlich einen anderen ,Kampf‘ $\mathrm{zu}$ bestreiten, nämlich jenen um die Aufmerksamkeit der Betrachter: Durch den Kontrastreichtum des Dekors mit seinen rauhen und glatten Flächen wurde das Geschriebene, das ja durchaus essentiell für das ,Funktionieren“

425 Athen, Akropolis-Museum, Inv. 13206. DAA $121=I G \mathrm{I}^{3} 850$ (um 470/60 v. Chr.?) = CEG I 272:

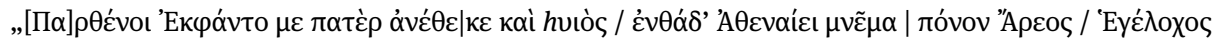
$\mu \varepsilon \gamma \alpha \dot{\lambda} \lambda \varepsilon<\varsigma>\tau \varepsilon$ /

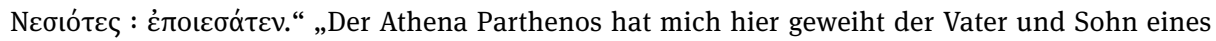
Ekphantos als Denkmal für die Qualen des Ares, Hegelochos, wegen der großen Gastfreundschaft und all der Tugend, die ihm zuteil ward, als er in der Stadt wohnte. Kritios und Nesiotes haben es beide gefertigt.“ (Übers. nach K. Hallof). Vgl. Krumeich 2007, 13 mit Anm. 40; DNO I 565 (zur Datierung nach 480 v. Chr.); Kaczko 2016, 345-354 Nr. 89 (mit Lit.).

426 Krumeich 2007, 13 mit Anm. 40; DNO I 565; Kaczko 2016, 345-354 Nr. 89.

427 Vgl. Kaczko 2016, 352.

428 Siehe hier Anm. 417.

429 Zur Rekonstruktion: Matthaiou 1988.

430 Ein solcher Bezug führt zudem ins Leere, wenn das Monument tatsächlich unmittelbar in den Jahren nach Marathon entstanden wäre, vgl. jetzt Arrington 2015, 45f., der die sekundäre Beschriftung vermutungsweise nach $480 \mathrm{v}$. Chr. ansetzt. 
des Monuments im erinnerungskulturellen Diskurs war, prägnant hervorgehoben, ohne dass man jedoch, wie gezeigt wurde, von seiner Rahmung im eigentlichen Sinne sprechen kann. Der Block als Träger, sein Dekor und die Schrift formen eng miteinander korrelierend ein beschriftetes Monument.

\section{Schlussbetrachtung}

Alles in allem - gegenüber einer allzu eng gefassten semantischen Ausdeutung der ,unfertigen‘ Oberflächengestaltung an der hier besprochenen Gruppe von spätarchaisch-frühklassischen statuarischen Monumenten aus Athen ist vor allem ihre dekorative Qualität geltend zu machen. Neben der allgemein zu beobachtenden Mode ,à la Ionienne dürfte ein spezifischerer ästhetischer Reiz - und das gilt sicherlich auch für die Ursprünge dieses Motivs in der spätarchaisch-ionischen Architektur - von der bewussten Interferenz mit den ,wohlgeordneten' architektonischen Formen wie der sorgfältig geglätteten Oberfläche eines Blockes bzw. eines kannelierten Säulenschaftes herrühren, in denen sich geradezu archetypisch das griechische Konzept des kosmos widerspiegelt. ${ }^{431}$ Dem entspricht das idealistisch formulierte Urteil Hans Lauters zum hellenistischen „Bossenstil“: „Daneben steht das sinnliche Vergnügen, das der Anblick rauher bzw. ,roher‘ Formen und Oberflächen einem Auge gewährt, das von subtilen Glättungen verwöhnt und schon übersättigt ist, welche die ,feine‘ griechische Architektur vor fast jeder anderen auszeichnet.“432 In diesem Sinne vermag das Aufkommen der dekorativen Unfertigkeit durchaus ein Zeitphänomen darzustellen, lässt sich doch am Ende der archaischen Epoche die behutsame Etablierung einer ,intentional disorder “im Bereich des Ornamentalen der visuellen Kultur beobachten. ${ }^{433}$ Für die Praxis des Beschreibens an den besprochenen statuarischen Monumenten spielte diese Entwicklung aber keine nennenswerte Rolle: Der neuartigen Variabilität der Oberflächengestaltung zum Trotz zeigt sich ein dezidiertes Festhalten an Bekanntem, indem sich die Disposition des Geschriebenen weiterhin eng an der Materialität ihres Trägers ausrichtete.

Bemerkenswert bleibt, soweit durch den erhaltenen Bestand an Monumenten fassbar, dass das Phänomens der dekorativen Unfertigkeit auf die Räume der (attischen) Heiligtümer bzw. auf die in ihnen aufgestellten Weihgeschenke beschränkt blieb. ${ }^{434}$ Denn obgleich das Erscheinungsbild der attischen Nekropolen in Form der

431 Zum Konzept des kosmos in der griechischen Architektur siehe etwa Marconi 2004. Zum Ornamentalen in der Architektur aus Sicht der modernen Architekturtheorie: Dürfeld 2008, bes. 72-77 zum Begriff des kosmos.

432 Lauter 1986, $289 f$.

433 Dietrich 2018c, 194-197 im Bezug auf spätarchaische Plastik und Vasenmalerei.

434 Für entsprechende Anatheme mit dekorativer Unfertigkeit aus Olympia und Delphi s. hier Anm. 357, die in ihrer Zahl jedoch weitaus geringer ausfallen. 
weit verbreiteten Stufenbasen wesentlich im Sinne des ,gebauten' statuarischen Monuments geprägt wurde, scheint doch die Basis der Phrasikleia-Kore und ihre Oberflächengestaltung ein folgenloser Vorläufer geblieben $\mathrm{zu}$ sein, sieht man von dem jüngeren Kenotaph der gefallenen Athener aus dem demosion sema ab. ${ }^{435} \mathrm{Da}$ das vorläufige Ende der aufwendigen privaten Grabrepräsentation in Attika um die Wende vom 6. zum 5. Jh. v. Chr. grosso modo mit dem erstmaligen Aufkommen der dekorativen Unfertigkeit an den Weihgeschenken zusammenfällt, während eine intensivere Verbreitung erst im frühen 5. Jh. v. Chr. nachgewiesen werden kann, vermag der fehlende Befund im Bereich der Grabdenkmäler nicht zu verwundern.

Dass die dekorative Unfertigkeit selbst in den Jahren nach der Mitte des 5. Jh. v. Chr. zumindest an den statuarischen Monumenten Athens aus der Mode kam, während sie sich in der zeitgenössischen Architektur der Polis einer neuen Beliebtheit erfreute, überrascht nur, wenn man ihre sprunghafte Verbreitung in der ersten Jahrhunderthälfte mit dem Narrativ der Perserkriegszerstörung erklären will. In ihrer Funktion zur repräsentativen bzw. ästhetischen Aufwertung der Statuenbasen mag sie schließlich von anderen Schmuckformen wie beispielsweise von z. T. aufwendig gestalteten Kopf- und Fußprofilen abgelöst worden sein. ${ }^{436}$ Allein, das Ende blieb ein vorläufiges: Spätere Rückgriffe, die allerdings deutlich entfernt sind von der bemerkenswert dichten chronologischen Geschlossenheit der hier besprochenen Gruppe, illustrieren den ungebrochenen ästhetischen Reiz der dekorativen Unfertigkeit. ${ }^{437}$

435 Siehe aber die Basis des Leanax hier Anm. 390. Allgemein zu den archaischen Stufenbasen aus dem Grabkontext: Kissas 2000, 42-69 Nr. A 8-39.

436 Zum Auftreten der profilierten Quaderbasis: Jacob-Felsch 1969, $49 \mathrm{f}$.

437 Exemplarisch zum frühhellenistischen Daochos-Weihgeschenk aus Delphi siehe Kapitel IV, S. 201-204; daneben u. a. etwa eine Reihe von Horos-Steinen aus dem Athener Kerameikos (siehe Stroszeck 2003 mit Verweisen), das spätklassische Weihgeschenk des Phaidimides von der Akropolis ( $I G I^{2}$ 4319), die für Q. Fufius Calenus wiederverwendete frühhellenistische Statuenbasis aus dem Amphiaraion von Oropos (I. Oropos 450 [Petrakos 1997] = IG VII 380) oder aber die von Herennia Procula signierte Statuenbasis für die Kopie des berühmten Eros von Thespiai (I. Thespiai 271; siehe Biard - Kalliontzis - Charami 2017, 750 Abb. 39). 


\section{Anhang: \\ Archaisch-klassische statuarische Monumente mit dekorativer Unfertigkeit}

\section{Stufenbasen}

\section{[2.1] Block der Stufenbasis des Alkibios}

Athen, Akropolis, Inv. 13262. FO: Akropolis, östlich der Propyläen.

'Ạূ̣íßıо

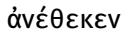

кıӨ

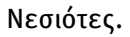

„Alkibios hat (dies) geweiht, der Kitharasänger, der Nesiote.“438

um 510-500 v. Chr.

Edd.: $\left.I G\right|^{3} 666$.

Lit.: DAA 84; Brunnsåker 1971, 136; Kissas 2000, 101f. Nr. B 25; Keesling 2003, 66f.; Franssen 2011, $213 \mathrm{f}$.

\section{Quaderbasen}

\section{[2.2] Fragment eines Basisblocks}

Athen, Akropolis-Museum, Inv. 13639. FO: Akropolis, beim Beulé-Tor.

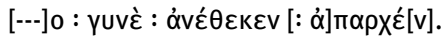

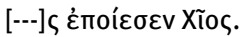

„[---] Gattin hat (dies) geweiht als Erstlingsgabe. [---]s von Chios hat es gefertigt.“

frühes 5.Jh. v. Chr.

Edd.: Kreeb 1986; IG I 830 bis.

Lit.: Kissas 2000, 283 Nr. C 81; Viviers 2002, 66f.; Keesling 2010, 126.

\section{[2.3] Basisblock}

Athen, Agora, Inv. I 5517. FO: als Spolie in hellenistischer Zeit verbaut in der Klepsydra als Teil der Brüstung.

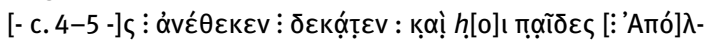

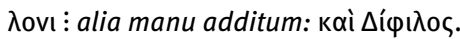

„[---]s hat (dies) als Zehnten geweiht und die Kinder dem Apollon. - und Diphilos.“

um 500-480 v. Chr.

Edd.: SEG 16, 14; IG I 950.

Lit.: Nulton 2003, 25; Keesling 2005, 399-401; Geagan 2011, 8 f. A8 (mit Lit.).

438 Die deutsche Wiedergabe der griechischen Inschriften richtet sich im Folgenden in aller Regel nach der von K. Hallof für die digitale Edition der $I G$ (http://telota.bbaw.de/ig/index.html) [Stand: 13.09.2019] angefertigten Übersetzung. Bei zu fragmentarisch erhaltenen Texten wurde auf die Angabe einer Übersetzung verzichtet. 


\section{[2.4] Basisblock des Kallias}

Athen, Akropolis-Museum, Inv. 7898. FO: Akropolis, südöstlich der Propyläen.

К $\alpha \lambda \lambda i ́ \alpha \varsigma$ hıтпо

„Kallias, Sohn des Hipponikos, hat (dies) geweiht.“

um 480 v. Chr.

Edd.: $I G I^{3} 835$.

Lit.: Studniczka 1907, 54-60; DAA 111; Kyle 1987, 203f. A 31.; Krumeich 1997, 91f.; Keesling 2003, $67,170 \mathrm{f}$.

\section{[2.5] Basisblock des Leagros}

Athen, Agora, Inv. I 1597. FO: beim Zwölf-Götter-Altar auf der Athener Agora.

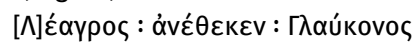

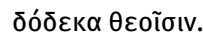

„Leagros, Sohn des Glaukon, hat (dies) geweiht den Zwölfgöttern.“

nach 480 v. Chr.

Edd.: SEG 10, 319; IG I3 951.

Lit.: Raubitschek 1939a; Rumpf 1964, 141; Davies 1971, 90-92 Nr. 3027; Kyle 1987, 222f. P 100;

Gadbery 1992, bes. 474; Krumeich 1997, 64-68; Kissas 2000, 89 Nr. B 10; Seaman 2002; Geagan 2011, 9 f. A9 (mit Lit.).

\section{[2.6] Fragment eines Basisblocks}

Athen, Akropolis-Museum, Inv. 13213. FO: Akropolis, zwischen Parthenon und Propyläen.

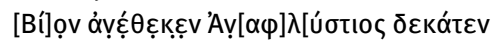

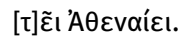

„Bion aus Anaphlystos hat (dies) geweiht als Zehnten der Athena.“

um 470-460 v. Chr.

Edd.: IG $\left.\right|^{3} 852$.

Lit.: DAA 119.

[2.7] Fragmente eines Basisblocks des Demostratides

Athen, Epigraphisches Museum, Inv. 6308+6371. FO: Akropolis.

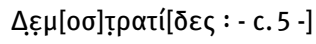

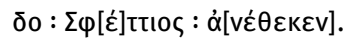

„Demostratides, Sohn des [---]des, aus Sphettos hat (dies) geweiht.“

um 470-460 v. Chr.

Edd.: $\left.I G\right|^{3} 853$.

Lit.: DAA 118.

\section{[2.8] Fragment eines Basisblocks}

Athen, Epigraphisches Museum, Inv. 6515. FO: Akropolis.

[---]Évns.

um 440 v. Chr.

Edd.: $/\left.G\right|^{3} 886$.

Lit.: DAA 145. 


\section{Rundbasen}

[2.9] Fragment einer Rundbasis des Opsios und eines zweiten Stifters

Athen, Akropolis-Museum, Inv. 13270. FO: Akropolis.

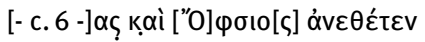

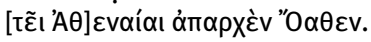

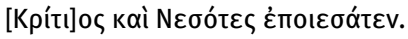

„[---]as und Opsios aus Oa haben (dies) beide geweiht der Athene als Erstlingsgabe. Kritios und Nes(i)otes haben es gefertigt.“

um 480-470 v. Chr. (DNO), um 475-465 v. Chr. (IG I')

Edd.: $\left.I G\right|^{3} 848$.

Lit.: DAA 160; Rumpf 1964, 144; Krumeich 2007, 12 f.; Stewart 2008, 391; Keesling 2009; DNO I 569.

[2.10] Fragmente einer achtseitigen Basis

Athen, Epigraphisches Museum, Inv. 6274 und ex-Agoramuseum, Inv. I 5408. FO: Akropolis und Agora.

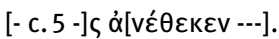

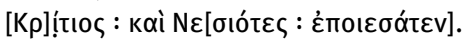

[---] hat (dies) geweiht [---]. Kritios und Nesiotes haben es beide gefertigt.“

um 475-465 v. Chr.

Edd.: IG I3 846.

Lit.: DAA 161a (Add.); Kissas 2000, 106f. Nr. B33; DNO I 568; Geagan 2011, 14 A22 (mit Lit.).

\section{Pfeilerbasen}

\section{[2.11] Pfeilerbasis des Euthydikos}

Athen, Epigraphisches Museum, Inv. 6324. FO: Akropolis, beim Erechtheion.

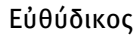

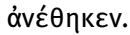

„Euthydikos hat (dies) geweiht.“

um 480-470 v. Chr.

Edd.: IG I 1337.

Lit.: DAA 294.

\section{[2.12] Pfeilerfragment der Mikythe}

Athen, Epigraphisches Museum, Inv. 6254. FO: Akropolis, bei der Südmauer.

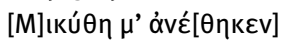

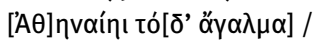

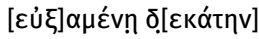

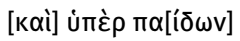

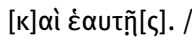

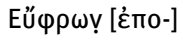

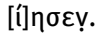

„Mikythe hat mich geweiht der Athene, dieses Standbild, da sie es gelobt, als Zehnten für die Kinder und für sich selbst. Euphron hat es gefertigt."

um 470-450 v. Chr.

Edd.: IG I3 857; CEG I 273.

Lit.: DAA 298; DNO I 659; Löhr 2000, 44f. Nr. 47; Kaczko 2016, 354-358 Nr. 90 (mit Lit.). 


\section{Säulenbasen}

[2.13] unkannelierte Säulenbasis

Athen, Epigraphisches Museum, Inv. 6298. FO: Akropolis.

Apıot[---].

um 500 v. Chr.

Edd.: IG $\left.\right|^{3} 737$.

Lit.: DAA 26; Kissas 2000, 243 Nr. B 212.

[2.14] unkannelierte Säulenschaftbasis des Xenokles

Athen, Akropolis-Museum, Inv. 6960. FO: Akropolis, bei der Nordmauer.

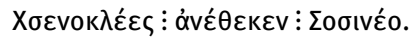

„Xenokles, Sohn des Sosineos, hat (dies) geweiht.“

um 500-480 v. Chr.

Edd.: IG $\left.\right|^{3} 690$.

Lit.: DAA 42; Kissas 2000, 232 Nr. B 184; Keesling 2005, 416-418 mit Abb 10.

[2.15] unkannelierte Säulenbasis der Empedia

Athen, Akropolis-Museum, Inv. 13396. FO: Akropolis, bei der Nordmauer.

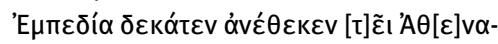

í $\alpha$ เ.

„Empedia hat (dies) als Zehnten geweiht der Athena.“

um 500-480 v. Chr.

Edd.: CEG I 250; IG $\left.\right|^{3} 767$.

Lit.: DAA 25; Kissas 2000, 244 Nr. B 217; Kaczko 2016, 264-266 Nr. 68.

\section{[2.16] unkannelierte Säulenbasis}

Athen, Epigraphisches Museum, Inv. 4047. FO: Voula (Westattika).

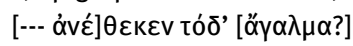

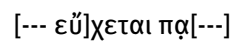

um 500-480 v. Chr.

Edd.: CEG I 310; IG I 973.

Lit.: Kaczko 2016, 470-472 Nr.127 mit Abb.127.

\section{[2.17] Säulenbasis des Kallimachos}

Athen, Akropolis-Museum, Inv. 6339. FO: Akropolis.

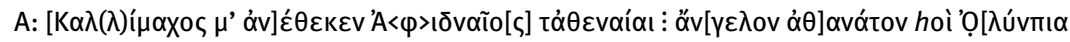

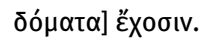

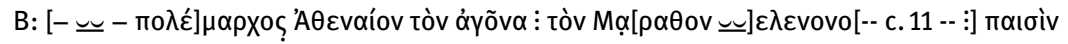

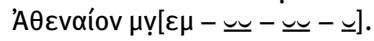

A: „Kal(l)imachos aus Aphidna hat mich geweiht der Athena, den Boten der Unsterblichen, die Olympische Häuser bewohnen.“

B: ,[---] Polemarch der Athener den Kampf in Marathon [---] den Kindern der Athener als

Denkmal [---].“

nach 490 v. Chr.

Edd.: CEG I 256; IG I 784 .

Lit.: DAA 13; Meiggs/Lewis 1988, 33f. Nr. 18; Kissas 2000, 195-198 Nr. B 154; Jung 2006, 72-84;

Keesling 2010; Franssen 2011, 161-163; Kaczko 2016, 281-291 Nr. 73 (mit Lit.). 
[2.18] unkannelierte Säulenbasis

Athen, Epigraphisches Museum, Inv. 5206. FO: evtl. Akropolis.

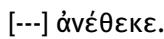

um 470-460 v. Chr. (?)

Edd.: $\left.I G\right|^{3} 861$.

Lit.: $D A A 38$.

[2.19] unkannelierte Säulenbasis des Diogenes

Athen, Epigraphisches Museum, Inv. 6312. FO: Akropolis, in der Westhälfte des Erechtheion.

$\Delta$ ıүév[ns]

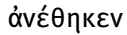

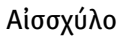

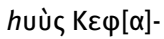

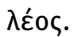

„Diogenes hat (dies) geweiht, Aischylos’ Sohn, aus Kephale.“

um 460-450 v. Chr.

Edd.: $\left.I G\right|^{3} 865$.

Lit.: DAA 46.

[2.20] unkannelierte Säulenbasis des Timotheos

Athen, Epigraphisches Museum, Inv. 6375. FO: Akropolis, südlich der Propyläen.

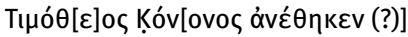

Av $\alpha \varphi \lambda u ́ \sigma \tau i o[\varsigma---]$.

„Timotheos, Sohn des Konon, aus Anaphlystos hat (dies) geweiht [---].“

um 460-450 v. Chr.

Edd.: IG I 863.

Lit.: DAA 47; Krumeich 1997, 111-113; March 2008, bes. $140 \mathrm{f}$.

\section{Rekonstruktion unsicher}

[2.21] Fragmente des Basisblocks des Peikon

Athen, Epigraphisches Museum, Inv. 6362. FO: Akropolis.

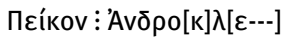

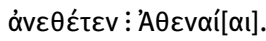

„Peikon (und) Androkl[e---] haben es beide geweiht der Athena.“

um 470 v. Chr. (?).

Edd.: IG I 843.

Lit.: DAA 131 a; Richter 1962, 13f.; Raubitschek 1973-1974, 620.

\section{[2.22] Fragmentarischer Basisblock des Pyres}

Athen, Akropolis-Museum, Inv. 6978. FO: Akropolis, verbaut in der Westtür des Parthenon, wo der größte Teil der Basis noch immer sitzt.

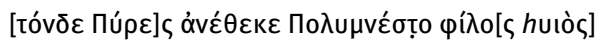

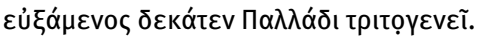

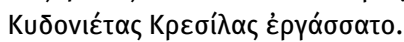

„Dieses (Standbild) hat Pyres geweiht, der liebe Sohn des Polymnestos, da er es gelobt, als

Zehnten der Pallas Tritogeneia. Kresilas aus Kydonia hat es gefertigt."

um 440 v. Chr. 
Edd.: CEG I 280; IG I3 885; vgl. Anth. Gr. XIII 13.

Lit.: DAA 133; Korres 1994, 90 MB 12 mit Abb.; Despinis 2008, 293f.; DNO II 1097; Kaczko 2016, 377-382 Nr. 98 (mit Lit.).

[2.23] Fragmentarischer Basisblock des Teles(tes)

Marathon, Museum, Inv. BE 34. FO: Marathon (Valaria).

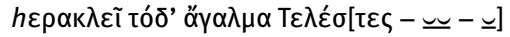

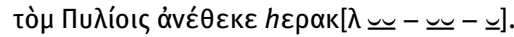

„Dem Herakles hat dieses Standbild Teles[tes ---] geweiht von den Spielen des Herakles bei den Toren [---].“

um 440 v. Chr.

Edd.: CEG I 318; IG I³ 1015bis.

Lit.: Matthaiou 2003, 191-197; Kaczko 2016, 500-504 Nr. 135 (mit Lit.).

[2.24] Fragment eines Basisblocks

Athen, Agora, Inv. I 5706. FO: zwischen Nordabhang der Akropolis und Areopag.

$[---] \lambda ı x[---]$

5. Jh. v. Chr.

Edd.: Geagan 2011, 13 A18. 
